\title{
Conservative Management for Patients with Sacroiliac Joint Dysfunction
}

\author{
Kyndall Boyle \\ Appalachian State University \\ USA
}

\section{Introduction}

Conditions involving one or both sacroiliac joints (SIJs) are often referred to as sacroiliac joint pain (SIJP), sacroiliac joint dysfunction (SIJD), or pelvic girdle pain (PGP). SIJP is defined as pain arising from intra-articular structures such as the anterior sacroiliac ligament, posterior sacroiliac ligament, interosseous ligaments, and articular cartilage in the SIJ. SIJD is a state of altered mechanics, either an increase or decrease from the expected normal or the presence of an aberrant motion. ${ }^{1}$ It includes pain arising from extra-articular structures that surround the SIJs such as the sacrotuberous, sacrospinous, and/or iliolumbar ligaments. Lastly, PGP is pain experienced between the posterior iliac crest and the gluteal fold, particularly in the vicinity of the SIJs. ${ }^{2}$ SIJP and SIJD are therefore considered subgroups of PGP. ${ }^{2}$

The prevalence of sacroiliac joint pain has been reported between $13-30 \% .3,4$ Specifically $13 \%$ of individuals with low back pain have pain arising from the SIJ as evidenced by relief of their pain after an intra-articular anesthetic block. ${ }^{3}$ Thirty percent of all patients seen in outpatient clinics have pain arising from the SIJs, $425 \%$ of pregnant women have PGP, and $7 \%$ of post partum women have "serious" PGP. 5

\section{Diagnosis}

\subsection{Subjective data}

Making a clinical diagnosis of a patient with certainty that pain is originating from the SIJs is challenging. ${ }^{1}$ Reliability and validity of many special tests (particularly motion palpation tests) are poor6, 7, and the existence of a Gold standard test is controversial. ${ }^{4,} 8$ Subjective history specifics, location of pain/symptoms, and special tests called provocation testing are helpful and important in this endeavor. Patients who complain of pain when they arise after long term sitting present a classic sign of pain from the SIJs. ${ }^{9}$ It is also common for patients to point directly over their left (L) and/or right (R) SIJs (posterior superior iliac spine (PSIS) region). This is referred to as Fortin's Finger Test. ${ }^{10}$ A complaint of unilateral pain (on one side only) rather than bilateral pain is also considered more likely to be coming from an SIJ. ${ }^{9}$ Another classic sign indicative of SIJ pain referral is the absence of lumbar pain above L5. 9 Pain perceived over one or both PSIS/SIJs and just lateral and/or inferior, in the buttock, is also a strong indicator of SIJP. ${ }^{11}$ This area is called Fortin's Area and was discovered and 
defined as three centimeters lateral to the PSIS/SIJ and ten centimeters caudal to the PSIS/SIJ, based on a study in which the SIJs were injected with a contrast medium (arthrography) to stimulate pain, and then the area of referred pain was mapped.11

\section{Special tests}

\subsection{Load transfer}

A myriad of special tests have been discussed in the literature, including a load transfer test ${ }^{12}$, many provocation tests designed to provoke pain in one or both SIJs, and motion palpation tests designed to assess asymmetry in SIJ motion and/or hyper- or hypomobility of the SIJs. The Active Straight Leg Raise Test (ASLR) assesses the ability of the patient to effectively transfer load between their lower limbs and trunk. ${ }^{12}$ This test can be used to help rule in pain arising from the SIJ(s) but is not limited to the SIJs. The ASLR test can also be used to assess many conditions involving the trunk and pelvis. The test is done with the patient lying supine. The clinician then asks the patient to raise their leg $5 \mathrm{~cm}$ off the supporting surface (plinth) (Figure 1) and determines how much effort was required on a scale of $0-5(0=$ No effort, $5=$ Max effort $) .{ }^{13}$ If the patient has optimal ability to effectively transfer load during the test, the leg will rise up effortlessly without any pelvic movement. The clinician observes for movement during the test and watches for compensatory movement resulting from instability. Examples of aberrant motion may include drawing the rib cage inward from over activation of the external obliques, flaring the lower ribs out from over activation of the internal obliques or thoracic extension from over activation of the

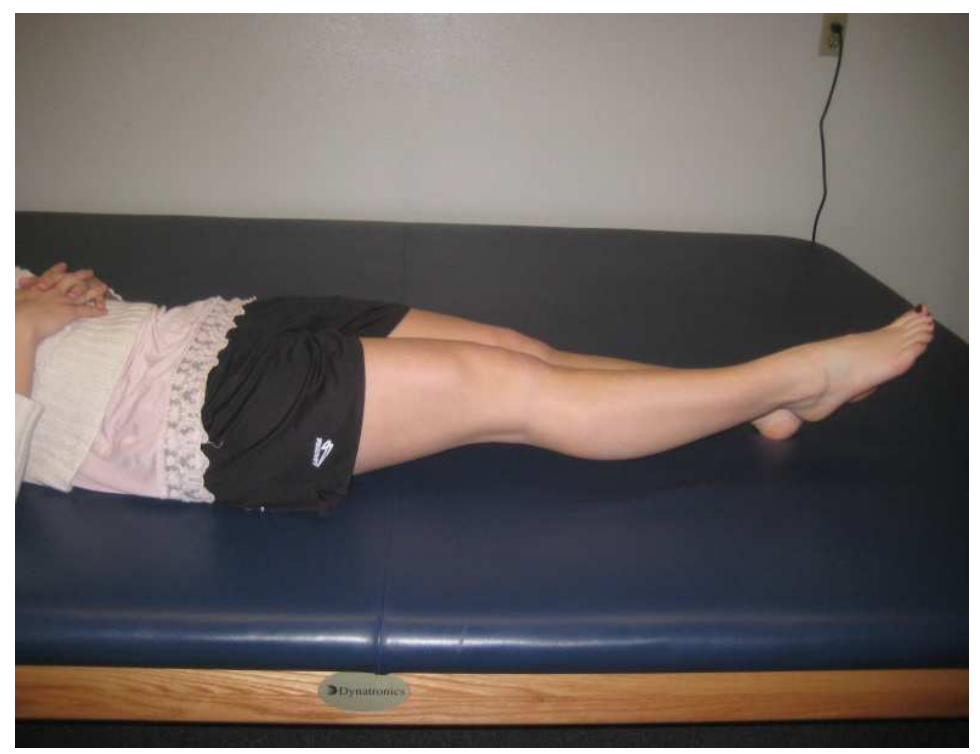

Fig. 1. Active Straight Leg Raise (ASLR) (step one)

Copyright @ Kyndy Boyle 2010, used with permission 


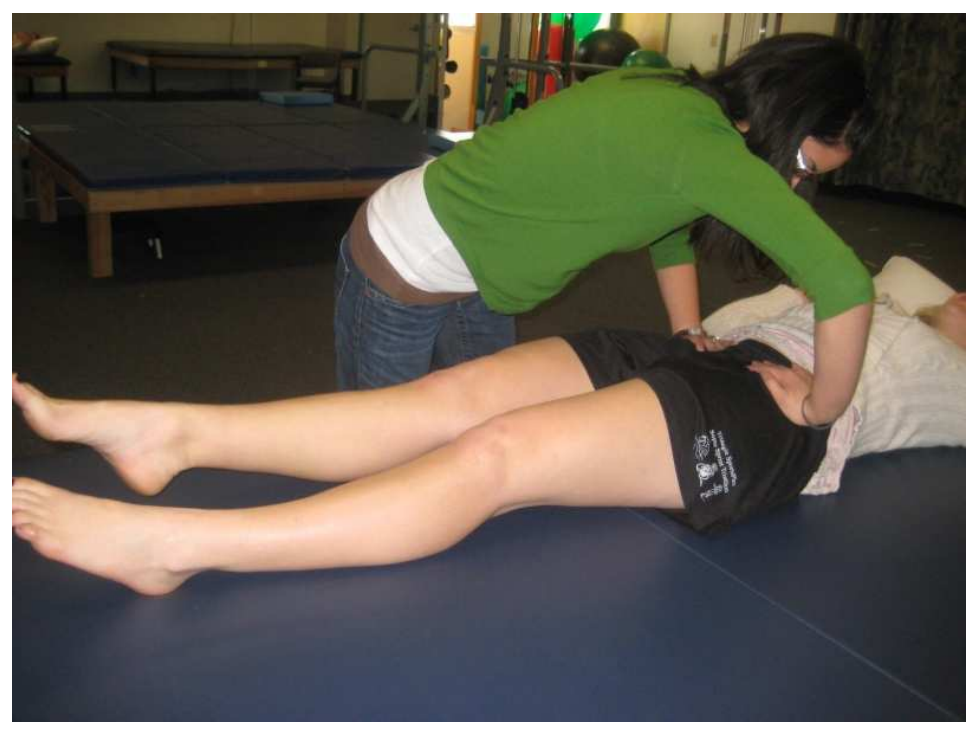

Fig. 2. Active Straight leg Raise (ASLR) with manual compression

Copyright (C) Kyndy Boyle 2010, used with permission

erector spinae. The abdomen may also bulge, potentially indicating that the patient is holding their breath during the test to compensate for poor load transfer. ${ }^{13}$ The clinician then repeats the test while applying manual pelvic compression in the area of compensatory motion (Figure 2). The clinician asks the patient if the heaviness or effort of lifting their leg has decreased. The test is positive if effort or heaviness is lessened or abolished with manual compression. A positive test indicates the need for greater stability around the SIJ, also called force closure, which will be discussed later in this chapter.

\subsection{Pain provocation tests}

Pain provocation tests (PPTs) such as Resisted Abduction, Patrick's Sign, Distraction, Gaenslen's, and Sacral Thrust have shown adequate reliability, sensitivity, and specificity, especially when performed as a cluster. ${ }^{8} 14,15$ PPTs are limited by the difficulty they present for the clinician to identify whether intra-articular or peri-articular structures are stressed by the tests. The possibility of false negatives due to physical properties of the tissues constitutes another limitation and may require PPTs to be held up to two minutes to avoid.16 From my observation over 21 years, they are seldomly held for that length of time in the clinic. Three or more positive PPTs appear to provide the highest discriminatory power, with a sensitivity of .85 and a specificity of $.76 .^{8} \mathrm{~A}$ few individual PPTs are recommended: The Thigh Thrust Test, also called the Posterior Shear Test, and the Compression Test. ${ }^{8}$ The Thigh Thrust/Posterior Shear Test has a reported sensitivity of .81 and specificity of .66 (Figure 3). The Compression Test has a reported sensitivity of .63 and specificity of .69 (Figure 4). 


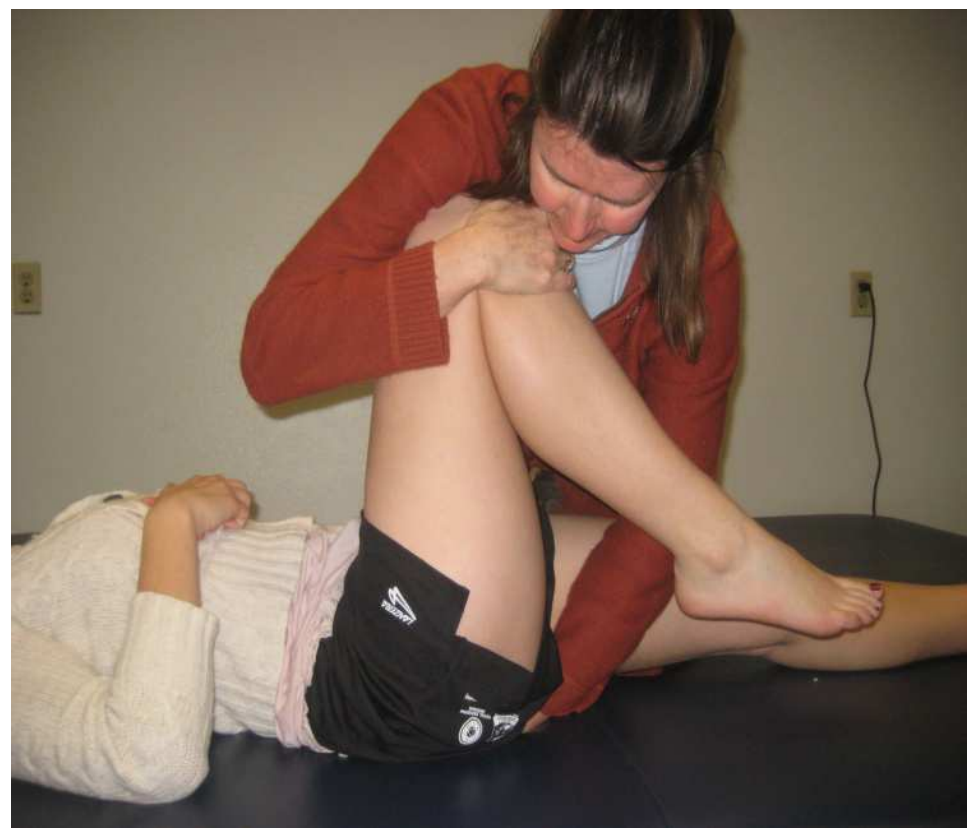

Fig. 3. Posterior Shear Test (Pain Provocation)

Copyright $@$ Kyndy Boyle 2010, used with permission

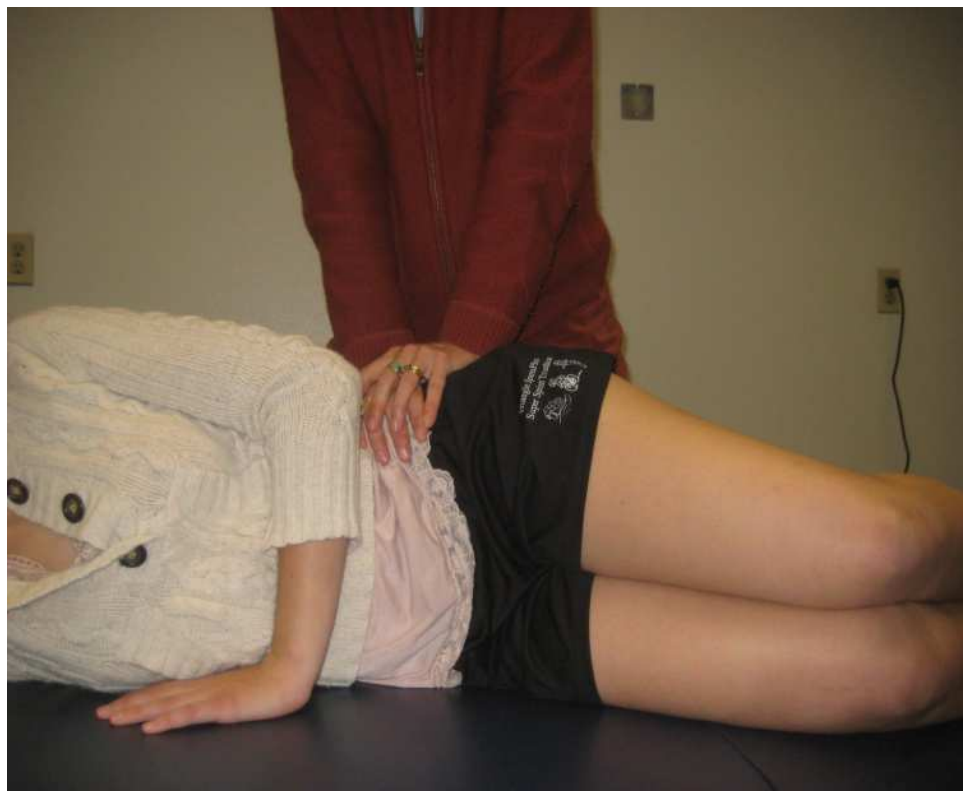

Fig. 4. Compression Test (Pain Provocation)

Copyright $@$ Kyndy Boyle 2010, used with permission 


\subsection{Motion palpation tests}

Motion palpation tests such as the Standing Flexion Test, Prone Knee Flexion Test, Supine Long Sitting Test, Sitting PSIS, and Heel-bank Test are not recommended for diagnosing patients with SIJP or SIJD.6, 7,17 Movement of the SIJ(s) cannot be reliably assessed by manual palpation, especially in weight bearing. The reliability, reported as Kappas between 0.19-0.37, is too low for clinical use.

Two opinions exist as to whether there is a gold standard for diagnosis of SIJP/SIJD. One opinion claims that anesthetic block procedures are the gold standard. ${ }^{18}$ This would require a physician to inject one or both SIJs with an anesthetic to determine if the patient's pain is abolished or lessened as a result of the injection. The other opinion claims that there is no gold standard. ${ }^{19}$ Anesthetic block procedures are considered effective if the patient's pain originates from intra-articular structures but not effective if their pain arises from extraarticular structures, such as accessory ligaments and muscle tissue that surrounds the joint. ${ }^{19}$

\subsection{Biomechanics/anatomy}

The sacroiliac joints involve the right and left ilium and their C-shaped articulations with the lateral sides of the sacrum. ${ }^{20}$ Each iliac surface is lined with fibrocartilage and each sacral surface is lined with articular/hyaline cartilage. ${ }^{20}$ Optimal SIJ function depends on optimal positioning and movement of six joints: both SIJ, the L5-S1 articulation, the pubic symphysis, and both hip joints (left and right acetabula and femoral heads). The SIJs are inherently stable and their design gives them the ability to safely transfer very high compressive loads under normal conditions. ${ }^{20}$ Although it was once believed that no movement occurred at the SIJs, several research studies have since demonstrated that this is not the case. ${ }^{21,22}$ Patients undergoing a lumbar fusion, will likely have a resulting increase in SIJ motion and stress, as these joints are just distal to the fused segments. ${ }^{23}$ Unilateral SIJ fusion has been documented to cause undesirable strain and load requirements on the contralateral SIJ.22 The amount of motion that may occur at the SIJs depends on whether or not the joints are loaded, and on the position of the hip joints in their range of motion (ROM). Research study results have also depended on whether fresh cadavers were used.22 SIJs that are loaded or in weight bearing are thought to move less than in non-weight bearing. ${ }^{21}$ SIJ motion appears to be greater when the hip joints are at their end range, versus a neutral position.

According to research, the SIJs may function as hip joints to get needed motion for gait and other movements which results in SIJ ligament strain..$^{24}$ The innominate bone will generally displace in the same direction as the hip, and act as an extension of the femur when the hip is at its end ROM and the innominate through the SIJ will attempt to gain more hip motion. ${ }^{24} \mathrm{~A}$ fresh cadaver study conducted within 24 hours of death of five donors reported sagittal plane motion of the SIJ between three to 17 degrees, and translation range was reported between four to eight millimeters (mm). ${ }^{22}$ Authors of another study that did not use fresh cadavers reported SIJ rotation in a non-weight bearing position to be 2.5 degrees and 0.2 degrees in a weight bearing position. ${ }^{21}$ Translation was reported as $1.6 \mathrm{~mm} .{ }^{21}$

A study using kinematic data with a magnetic tracking device reported that the right SIJ is capable of greater ROM than the L SIJ. ${ }^{24}$ This study was done on 40 subjects including both 
females and males from 18-35 years who were pain free in their SIJs/low back and had no history of injury. ${ }^{24}$ Sagittal plane motion was reported as $60 \%$ greater on the $\mathrm{R}$ than the $\mathrm{L}$ in a cadaver study using Computerized Tomography (CT) on subjects from 52-68 years. The average motion on the right was eight degrees and five degrees on the left. ${ }^{22}$ No explanation for the increase in $\mathrm{R}$ sided motion was given.

It was once believed that an increase in bilateral laxity of the SIJs as a result of pregnancy from the release of the hormone relaxin was associated with SIJP. This belief however was disputed by a study by Damen who reported that increased motion/laxity of the SIJS is not related to pain for pregnant women. ${ }^{25}$ He reported however that increased laxity of just one SIJ was related to pain. Pregnant women with "moderate to severe" SIJP/PGP had more laxity in one SIJ compared to the other SIJ based on Doppler imaging of vibrations in threshold units. The study was completed on 163 subjects.

Concepts referred to as form and force closure can aid in the stability of the SIJs. ${ }^{13,26}$ Form closure is stability achieved by virtue of the shape, structure and orientation of the bones that make up the joints. The $\mathrm{R}$ and $\mathrm{L}$ iliums interlock on either side, with the sacrum bone nestled in between. This osteological design contributes to the inherent stability of the joints. For optimal form closure however, there needs to be optimal position of each ilium on each side of the sacrum and/or each side of the sacrum on each ilium. Based on my 21 years of practice as a licensed physical therapist, some patients will complain that they feel their SIJ slipping, moving, rubbing or going out of place, usually on the right. These subjective reports may indicate that optimal form closure has been lost, at least temporarily.

Interventions to address positional faults of the SIJ include specific muscle activation using therapeutic exercises, muscle energy techniques and joint manipulation techniques. Joint manipulation techniques may improve pain and function however they do not change the position of the sacrum in relation to the ilium based on Roentgen Stereophotogrammetric Analysis (RSA). ${ }^{27}$ The benefits of these interventions will be discussed in more detail toward the end of this chapter.

Force closure is the concept of compressive forces that are exerted across the joints to aid in stability. ${ }^{13}$ SIJP has been associated with both insufficient force closure and excessive force closure coming from motor activation of lumbopelvic and surrounding musculature such as the pelvic floor. ${ }^{28}$ Forces that are perpendicular to the joint surface have the most optimal angle of force to contribute to joint stability. These forces are often generated intrinsically by contracting muscle and can also be generated extrinsically by external supports such as a sacroiliac joint belt. There are several different muscles that act to compress and control the SIJs to enhance their stability and stiffness which allows for effective load transfer via the pelvis during a variety of functional tasks. Muscles that have been described as contributing to force closure include the gluteus maximus (GM), piriformis, and coccygeus of the pelvic floor, respiratory diaphragm, transverse abdominus (TA) and the internal oblique (IO). 12, 29 3031 Those muscles that are transversely oriented such as the TA, IO, piriformis and coccygeus are positioned the best to contribute to increased SIJ ligament stiffness. When laxity of ligaments associated with the SIJs decrease and the stiffness increases, then force closure of the SIJs will increase. Richardson reported that independent contraction of the TA affects SIJ laxity/stiffness more than contraction (bracing) of all the abdominal muscles at once. ${ }^{30}$ 
The GM provides stability to the lumbopelvic region ${ }^{13}$ and to the hip joints ${ }^{32}$ and the deep fibers of the GM cross the SIJs. ${ }^{33}$ The architecture of the piriformis lends itself to an angle of pull roughly transverse to the joint via its proximal attachment to the inferior lateral sacrum and the superior greater trochanter of the femur. ${ }^{34}$ Even though the coccygeus is inferior to the SIJs, its line of pull from the proximal attachment site at the ischial spine to the distal attachment of the coccyx and anococcygeal ligament is transverse to the SIJs. ${ }^{34}$

The R and L respiratory hemi-diaphragms do not cross the SIJs however they are considered inner-core muscles. ${ }^{13}$ If one hemidiaphragm pulls on the distal attachment site on the lumbar vertebrae more than the other, the entire sacrum could orient itself in contralateral rotation. The diaphragm and its position and contraction along with abdominal muscles influence the degree of intra-abdominal pressure (IAP) which can also aid in stability across the SIJs. Research by Hodges has elucidated the role of the diaphragm in increasing IAP prior to limb movement that occurs simultaneously with TA activation. ${ }^{35}$ The respiratory diaphragm's contraction occurs before limb movement to aid in trunk stability. When demands are placed on the trunk such as the anticipation of fast upper extremity movement, the respiratory diaphragm is used more for stability of the trunk and for postural control than it is used for respiration. The diaphragm's primary role is for respiration and its role as a postural muscle or lumbar stabilizer is secondary. ${ }^{35}$ When the diaphragm contracts too much, it can become more linear and loose its position and shape for the area of the diaphragm known as the zone of apposition (ZOA). The ZOA is the area of the diaphragm that encompasses the cylindrical portion of the diaphragm which corresponds to the portion directly apposed (adjacent) to the inner aspect of the lower rib cage. ${ }^{36} 37,38$ During exhalation, the ZOA should account for approximately $30 \%$ of the surface area of the diaphragm. ${ }^{36}$ Importance of the ZOA is multifactoral. The ZOA is important because when the ZOA is decreased compared to optimal there is less descent of the dome of the diaphragm and less appositional diaphragm forces. ${ }^{39}$ The diaphragm is therefore less effective during its inspiratory muscle action and has less ability to expand the lower rib cage. ${ }^{40}$ Decreased ZOA will result in less IAP and may result in a short diaphragm. ${ }^{41}$ Exercise tolerance has been reported to decrease with suboptimal (decreased) ZOA. ${ }^{42}$

There is a polyarticular chain of muscles where the diaphragm overlaps with the psoas muscle at the distal attachment of the diaphragm and the proximal attachment of the psoas. ${ }^{34}$ The diaphragm can pull the lumbar spine up/cephalad/superior and forward/anterior and the psoas can pull the spine down/caudal/inferior and forward/anterior. (Figure 5) This situation would result in a decrease in IAP, an increase in lordosis and anterior pelvic tilt and lengthening of the abdominals. ${ }^{41}$ This excessive pull on the diaphragm occurs with splinting or breath holding of the diaphragm and during situations of hyperinflation. ${ }^{43}, 44$

There is a relationship between suboptimal or faulty respiration, motor control strategies, posture and SIJP. ${ }^{28} \mathrm{O}^{\prime}$ Sullivan et al. investigated the relationships between breathing and motor control strategies for patients with SIJP during an Active Straight Leg Raise (ASLR) test using real time ultrasound and spirometry. They reported that the subjects with SIJP have suboptimal breathing as evidenced by an increase in their respiration rate compared to controls. They also reported that subjects with SIJP had suboptimal core muscle function as evidenced by depression of the pelvic floor rather than optimal and expected pelvic floor elevation which was seen in the controls. Additionally diaphragm excursion was decreased compared to the controls. The authors noted that the subjects with SIJP had altered motor 


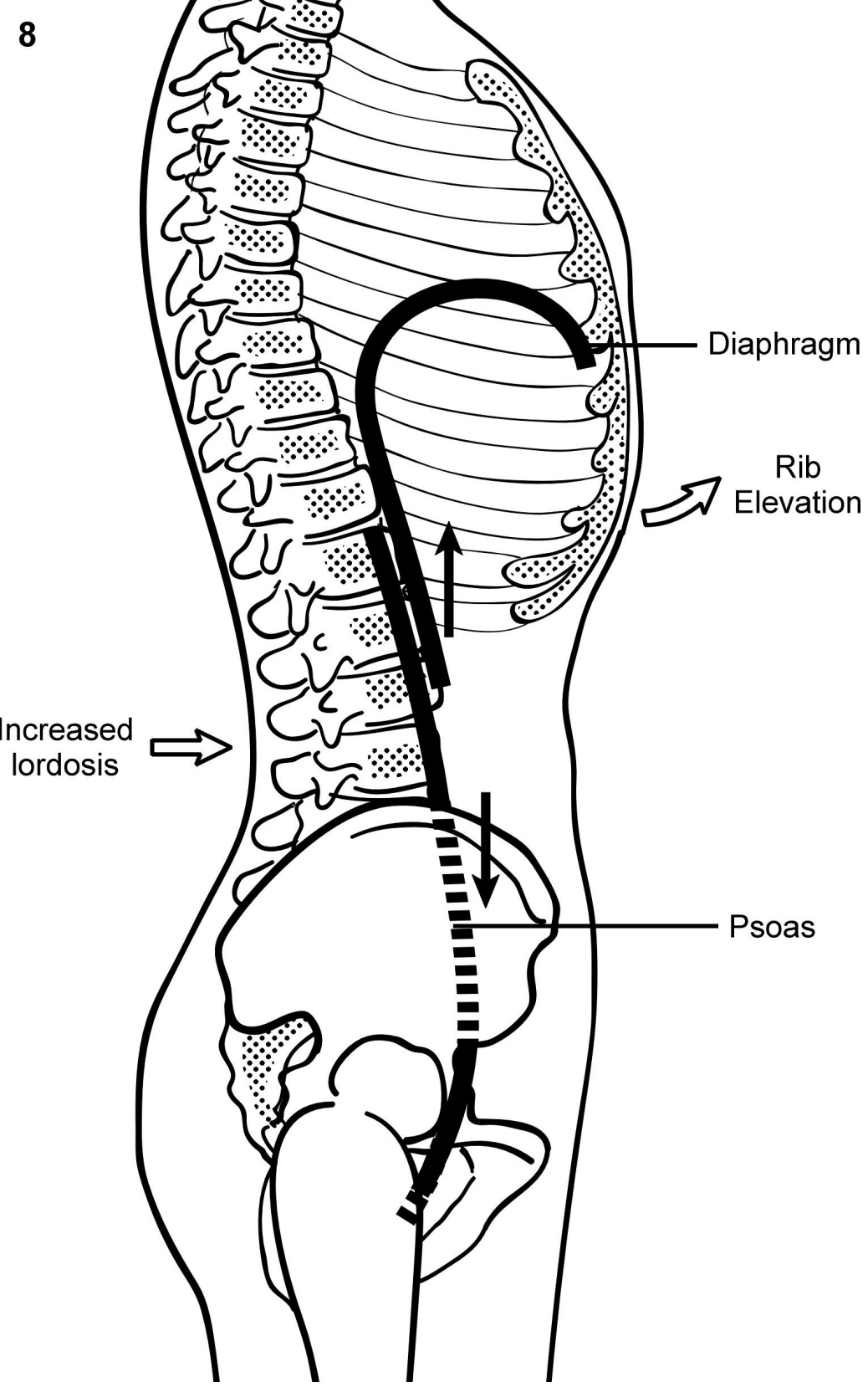

Fig. 5. Sagittal view of the influence of the pull of the diaphragm and psoas (polyarticular chain) on the spine, pelvis and ribs: increased lordosis/extension, hip flexion/anterior pelvic tilt and rib elevation/external rotation.

Copyright (C) Kyndy Boyle 2007, used with permission 
responses during the ASLR as they attempted to compensate for their lack of ability to transfer load through their lumbopelvic region secondary to suboptimal form and/or force closure. When the ASLR was repeated with manual compression on the subjects with SIJP, their responses normalized: respiratory rate slowed, pelvic floor did not depress and their diaphragm had more excursion. O'Sullivan et al. described three possibilities for their findings. The first possibility was that subjects with SIJP and suboptimal form closure across one or both SIJs may have been a result of a lesion in their ligamentous system which required their diaphragm to be recruited to generate IAP which led to suboptimal respiration. The second possibility was the suboptimal force closure was a result of pain or a motor control deficit that lead to substitution strategies and splinting of the diaphragm which resulted in suboptimal respiration. The third possibility was reasoned as a possible compromise of both form and force closure mechanisms. The recommendations that O'Sullivan et al. make in conclusion of their study is that "intervention to integrate control of deep abdominals with the pelvic floor and diaphragm may be effective for patients with SIJP." The authors however do not give any examples of exercises that patients could do to achieve this aim.

A biomechanical theory to explain both $\mathrm{R}$ and L sided SIJP was developed by Ron Hruska PT. ${ }^{45-48}$ His theory supports the concept of the SIJ functioning as a hip joint and also explains why the right SIJ may move more in the sagittal plane than the L SIJ. Through Hruskas 33 years of full time practice as a physical therapy clinician, he has recognized a common pattern of asymmetry that may contribute to a myriad of musculoskeletal conditions including SIJP/SIJD. ${ }^{45}$ Other musculoskeletal conditions that the asymmetrical pattern may contribute to include thoracic outlet syndrome, ${ }^{44}$ low back pain, ${ }^{47,}{ }^{49}$ sciatica, ${ }^{46}$ trochanteric bursitis, 50 asthma ${ }^{51}$, pelvic floor pain and proximal hamstring strain. ${ }^{52}$ This pattern is called the Left Anterior Interior Chain (L AIC) pattern which gives focus to a polyarticular chain of muscles that is anterior to the spine and interior (deep) in the body, which includes the diaphragm and psoas. 45,5347 The belief is that this chain of muscles becomes imbalanced because of several factors such as the asymmetrical position of organs, asymmetrical forces exerted by the diaphragm and hemisphere dominance. 45 The pattern is thought to manifest in both right handed and $\mathrm{L}$ handed individuals. The liver which weights approximately 3.5 pounds in an average adult is on the right side of the body (unless an individual is born with their organs reversed). The liver hangs down from the diaphragm by the transverse and falciform ligaments which anchor the proximal attachment sites of the right hemi-diaphragm and help to preserve the area of the right hemidiaphragm known as the right ZOA. The absence of a liver on the $\mathrm{L}$ side of the body creates a situation where the L diaphragm is not as well anchored and therefore the area of the diaphragm known as the ZOA can become decreased, the L ribs may become more elevated/externally rotated relative the $\mathrm{R}$ side and the $\mathrm{L}$ abdominals may become more lengthened relative to the right side. ${ }^{41,} 45$

The influence of the asymmetrical pull of the hemi-diaphragms on the ribs can often be seen with visual observation of the anterior inferior rib angle which is often wider on the $L$ than the $\mathrm{R}$ and the ribs may appear more protruded on the left side. ${ }^{54}$ The asymmetrical distal attachment site of the L (anterior bodies of L1-2) versus R hemidiaphragm (anterior bodies of L1-3) and the inherent difference in the size of the large $R$ central tendon versus the smaller L central tendon contribute to asymmetrical pull of the hemi-diaphragms on the 
spine. Asymmetrical hemidiaphragm on the spine could influence the SIJs along with many other areas of the body. This asymmetrical pattern when severe enough to be ten degrees or more of curvature is commonly known as idiopathic acquired scoliosis (IAS). ${ }^{55}$ The L AIC pattern therefore compliments the common scoliosis pattern. The pattern of IAS is documented between $85-98 \%$ with right thoracic curves rather than left and possibly $\mathrm{L}$ lumbar curves rather than right. ${ }^{56}$ The literature doesn't explain why the right thoracic curves are much more common than L thoracic curves; however the reasoning behind a $\mathrm{L}$ AIC pattern does. This reasoning includes the asymmetry of organ placement, asymmetrical pull of the hemi-diaphragms; lateralization of the brain and the direction of pelvic movement influences the direction of vertebral and rib movement. The greater pull of the left hemidiaphragm is thought to contribute to an asymmetrical lumbar-pelvic-sacralfemoral position. This position includes an anterior pelvic tilt and forward pelvic rotation on

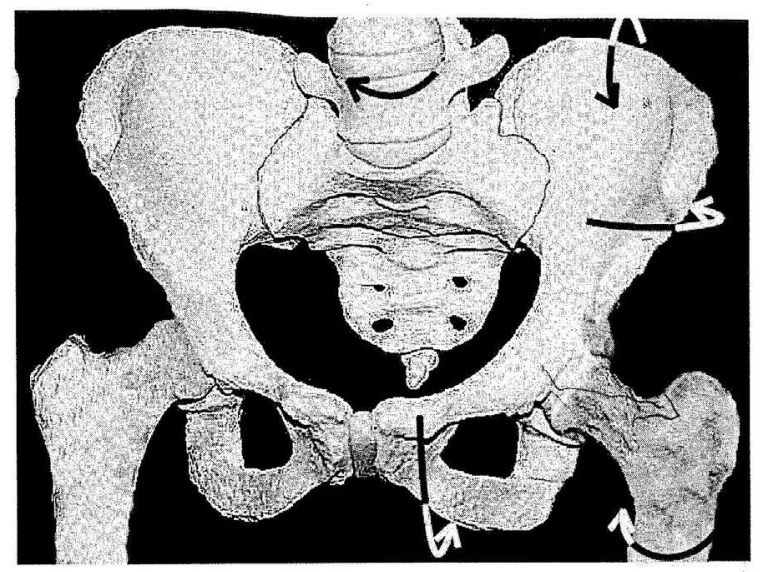

Anterior view of an anterior and forward positioned left innominate with accompanying right sacral torsion.

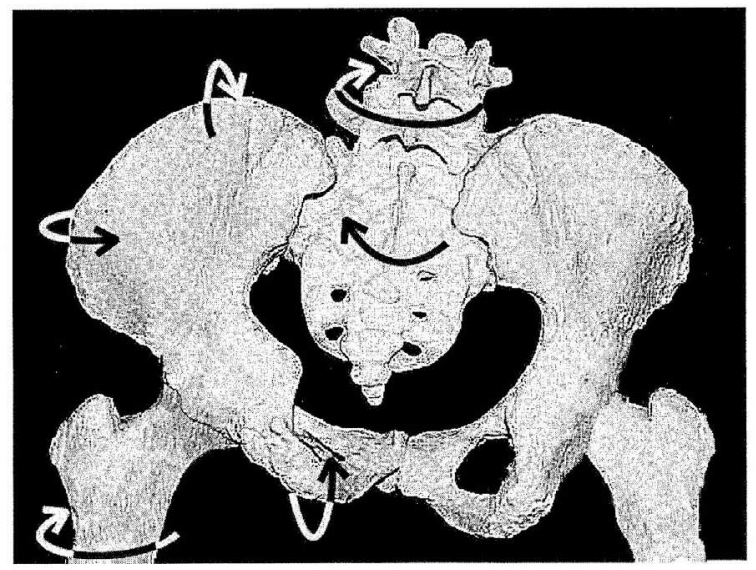

Posterior view of an anterior and forward positioned left innominate with accompanying right sacral torsion.

Note:

- Raised left ischium

- Right SI distraction

- Rotation of sacrum, L5 and

L4 to the right

- "Out" flare of left innominate

- Closure of left obturator

foramen

Fig. 6. Frontal plane anterior and posterior views of the lower lumbar-pelvic-sacral-femoral position in a Left Anterior Interior Chain Pattern (L AIC) Copyright (C) Postural Restoration 2007, used with permission 
the left side (i.e. left hemilordosis). Along with this position would be lower lumbar vertebrae and the sacrum oriented in right rotation. The right hip in a closed chain would therefore be in adduction and oriented in internal rotation. The left hip would be in abduction and either neutral in the hip joint (rather than rotated) or in compensatory external rotation to realign the foot in the sagittal plane. The pelvic position of left anterior pelvic tilt (sagittal plane) and forward rotation (transverse plane) compliments the position of right thoracic and left lumbar IAS. (Figure 6) A pelvic position of right APT and forward rotation would not direct the spine into left lumbar rotation or compensatory right thoracic rotation.

The IAS and L AIC patterns are supported by two Spine Journal articles. Kouwenhoven et al. used CT on 50 subjects to investigate whether or not an inherent pattern of asymmetry of the spine was present in individuals without diagnosed scoliosis.. ${ }^{57} \mathrm{He}$ reported right rotation of lumbar-thoracic vertebrae (L5-T5) and L rotation of upper thoracic vertebrae (T3$4)$. The opposite pattern was reported in a separate study $(\mathrm{N}=37)$ where subjects with organ reversal (situs inversus totalis) were sampled and the same CT measurements were made. 58 This inherent pattern was left lumbar rotation (L5-T5) and R upper thoracic rotation (T3-4). These inherent patterns of spinal rotation were attributed to organ placement including the heart. Hruska's identification of the pattern has lead to development of conservative physical therapy management for a myriad of conditions that are believed to relate to it and this approach is called Postural Restoration. ${ }^{45}$

Clinicians trained in Postural Restoration often use the Ober's Test to assess triplanar pelvic position. ${ }^{45}$ If the pelvis is neutral then the leg should be able to adduct at the hip joint below the horizontal. If the pelvis is not neutral (i.e. the acetabulum over the femoral head is not in an anatomical neutral position) then when the leg is moved by the clinician during the test, a bony block may be felt during the external rotation/abduction phase of the test and/or during the adduction phase of the test. The bony block may indicate an abutment of the femoral neck on the cotyloid rim of the acetabulum. An increase in either hip flexor tone may be felt by the clinician during the hip extension phase of the test or an increase in tone of the abductors during the adduction phase of the test are additional possible findings during the Ober's Test. A positive test on the left side is common for patients in a typical L AIC pattern and it is usually interpreted by the clinician as a left anterior tilt and/or left forward rotation of the pelvis.46, 47, 50 A positive test on both the right and left sides is interpreted as a bilateral anterior pelvic tilt which is seen in patients with a Posterior Exterior Chain (PEC), which is discussed at the end of this section (page 14). This use of the test is relatively new and different from the traditional use which is to determine if there is shortness of the iliotibial band/tensor fascia latae. ${ }^{59}$ Since the use of the Ober's Test by those clinicians trained in Postural Restoration is different in the reason to do the test, the interpretation of a positive test and in the intervention for a positive test, the Postural Restoration Institute ${ }^{\mathrm{TM}}$ began using a new name, the Adduction Drop Test (ADT) to avoid confusion. This ADT test is being used therefore as a reflection of triplanar position of the pelvis which does have some preliminary research support. ${ }^{60,61}$

The L AIC pattern is thought to relate to SIJ instability in that the pattern leads to over use of the $\mathrm{R}$ leg for standing where the center of gravity (COG) is shifted to the right. The COG shifted right would place the $\mathrm{R}$ hip into adduction and oriented into internal rotation. The $\mathrm{R}$ adductor magnus may become over active (hypertonic) and short. In order to get more internal rotation at the hip in the position of relative hip IR (acetabulum over femur) the 
ilium would have to attempt forward motion which would cause tensile forces across the posterior SIJ. A gap or greater distance between the ilium and sacrum is seen on a MRI for a patient who was seeking physical therapy for her R SIJP. (Figure 7) Therefore, if the R SIJ begins to move too much it may become painful. If however the ligaments and muscles are stable and strong and continue to provide enough stability to the right SIJ to avoid pain, it is possible that the $\mathrm{R}$ hip joint itself may begin to move too much, but in a faulty position of the acetabulum over the femur. This situation may lead to anterior medial hip impingement commonly referred to as femoral-acetabular impingement (FAI). ${ }^{62}$ It is possible as evidenced by my personal experience, to improve a patient's R SIJ stability with therapeutic exercise and then if discharged too early, the patient may begin to complain of $\mathrm{R}$ hip impingement.

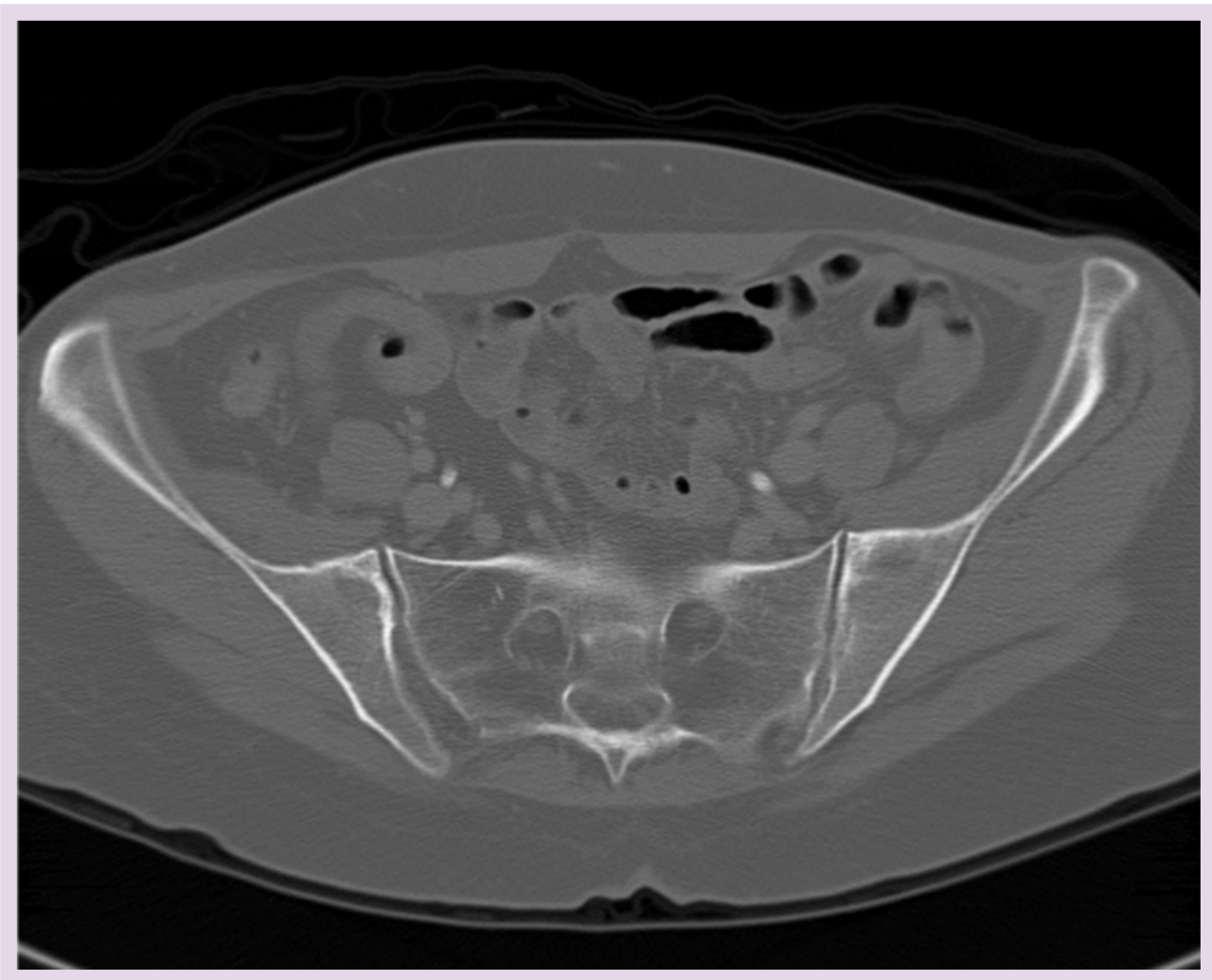

Fig. 7. Transverse plane view of the Sacroiliac Joints on Magnetic Resonance Imaging (MRI). The image shows a greater opening/gapping on the right side.

Copyright $(C)$ Postural Restoration Institute ${ }^{\mathrm{TM}}$ used with permission, www.posturalrestoration.com

The pelvic position with this L AIC pattern is thought to result in part from the asymmetrical pull on the spine by the diaphragm and also from the weaker $\mathrm{L}$ abdominals which would result in an anterior tilt and forward rotation of the $\mathrm{L}$ innominate relative to the $\mathrm{R}$ and sacrum orientation to the right. ${ }^{20,45,47}$ If the $\mathrm{L}$ femur stays neutral in the 
acetabulum when the pelvis goes anterior and forward it would appear to be oriented inward with toes pointing inward to the midline. This position often results in compensatory L hip external rotation (ER) to reorient the foot on the ground and the femur back into the sagittal plane.45, 62, 63 When the L hip external rotators become over active because of this compensatory L hip position, the L hip is in abduction and external rotation (ER). The L ilium may begin to function as a L hip joint to increase the available hip ROM

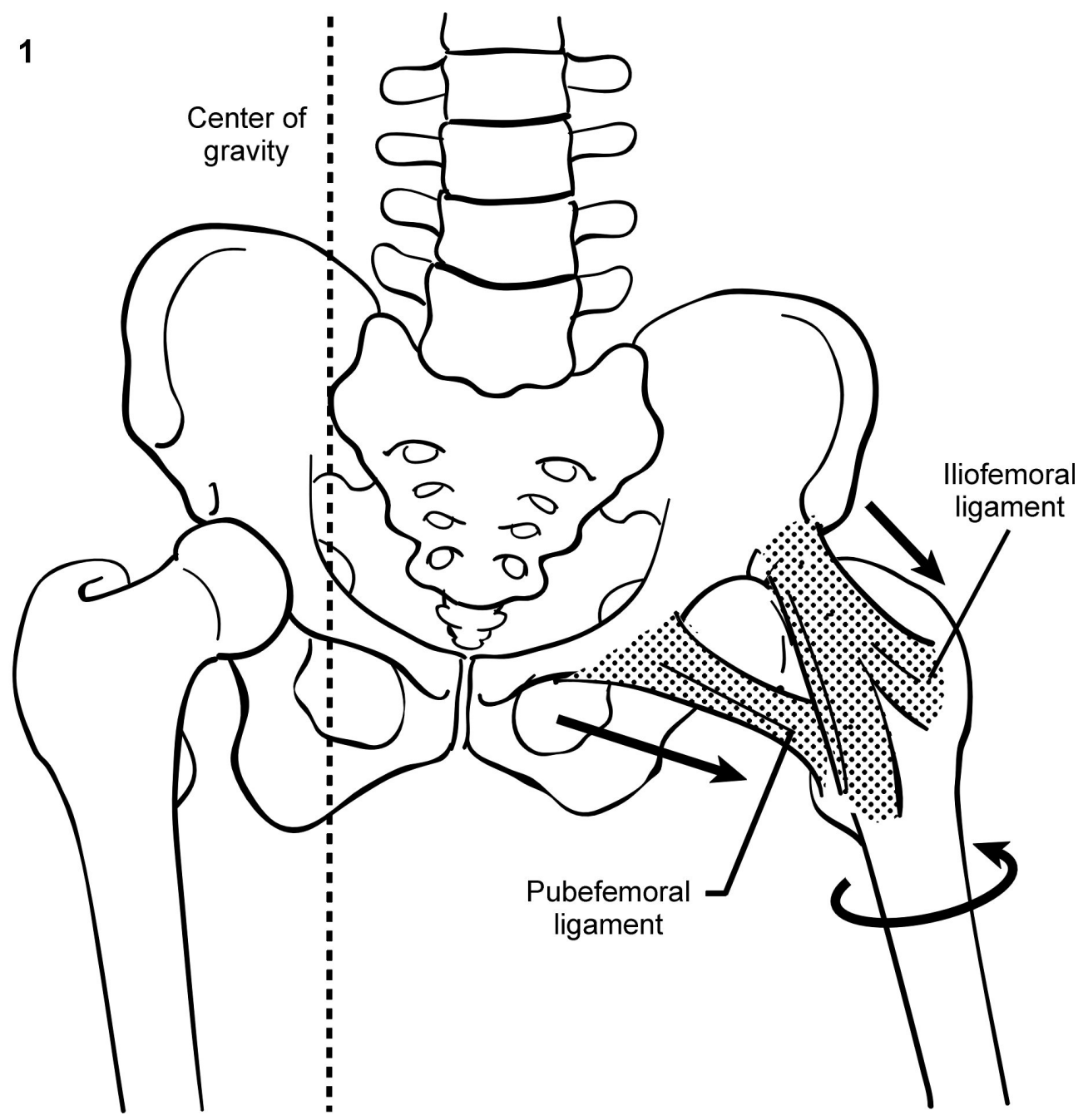

Fig. 8. Compensatory left hip external rotation (ER) associated with a L AIC pattern resulting in over lengthening/laxity of the iliofemoral and pubofemoral ligaments. The left femur (F) moves on the left acetabulum (A), therefore left FA ER.

Copyright @ Kyndy Boyle 2007, used with permission 
and the left SIJ may become unstable. If however, the excessive motion occurs at the hip rather the L SIJ, the anterior hip ligaments/capsule (pubofemoral and iliofemoral ligaments) may become stretched out and loose creating instability of the L anterior hip and may be associated with L anterior superior hip impingement. ${ }^{64}$ (Figure 8)

A pattern that may overlay a L AIC pattern is called a Posterior Exterior Chain (PEC) pattern. ${ }^{45,48}$ The PEC terminology is used for a patient who has a bilateral anterior pelvic tilt and excessive lumbar lordosis as a result of over activity of muscles in the posterior back. The muscles that make up the PEC include the latissimus dorsi, quadrates lumborum, posterior intercostals, serratus posterior and ilocostalis lumborum. ${ }^{48}$ These patients often have the inability to touch their toes, and/or reverse the extension/lordosis curvature of their spines. They may also lack the ability to do a full squat. Management of patients with a PEC pattern associated with SIJP and specific management and clinical reasoning for patients with SIJP on the right versus the left SIJ will be discussed toward the end of this chapter.

\section{Traditional interventions for SIJP/SIJD}

Interventions specifically for SIJP/SIJD (rather than general PGP) that appear in peerreviewed literature include SIJ manipulation, muscle energy techniques, SIJ belt, patient education regarding the pain cycle, moist heat, soft tissue massage, electrical stimulation and therapeutic exercise including activation of the transverse abdominus, stretching exercises and aquatics. In spite of the prevalence of patients with SIJP/SIJD and the relatively long length of time of recognition of SIJ conditions, there is a paucity of published literature. Furthermore, published literature pertaining to the SIJs is primarily in the bottom half of the evidence pyramid. The good news however is that all of the listed interventions have shown to reduce pain and disability to varying degrees. The challenge is that the authors do not always describe the therapeutic exercise so the results are difficult to interpret and the studies are not replicable. With the exception of two randomized controlled trials (RCT), readers are not able to infer cause and effect with the existing studies. Lastly, Stuge believes that interventions should be based on a theoretical framework. 65

A RCT published by Chiropractors investigated two different types of chiropractic manipulation for the SIJ: manual versus mechanical (with a piece of equipment). The Chiropractors studied 60 subjects using diagnostic criteria of a painful sulcus on palpation and a positive provocation test. They were treated for four visits over two weeks and function was measured with an Oswestry Disability Index (ODI) at the initial visit and three weeks post intervention. There were no differences between groups. ${ }^{66}$ Stuge et al published the results of an RCT done on 81 subjects with PGP post partum with a positive ASLR and a positive provocation test. They studied two groups: the control group (CG) received "general interventions" that included massage, relaxation, joint mobilization, manipulation, electrical stimulation, hot packs and strengthening exercises. Specific parameters of the interventions including dosage and the specific exercises used were not described. The exercise group received all the treatments as the CG plus instruction in TA, multifidus, gluteus maximus (GM), latissimus dorsi (lats), 
obliques, erector spinae, quadratus lumborum (QL), hip adductors and hip abductor exercises. Again the specific ways the exercises were done including dosage parameters were not described. The outcome measure was taken at initial, 20 weeks, one year, and two years. The EG had superior outcomes for reducing pain as measured by the Visual Analog Scale (VAS), improved function as measured by the ODI, and improved quality of life as measured by the SF-36.65

Published case series have been reported with some improvements in pain and function. Osterbauer investigated chiropractic manipulation on ten subjects with positive provocation testing and were followed for 18 visits over six weeks. ${ }^{67}$ The improvements in function (ODI) and pain (VAS) were reported at six weeks and one year. Hall was a physical therapist who reported on a case series of two who had a positive ASLR test and positive provocation tests. These subjects were managed with muscle energy techniques, TA and multifidus activation, isometric hip abduction/adduction, activation of lats, GM and abdominal crunches. They were also instructed in the use of a SIJ belt. These subjects were seen from five to seven visits over seven to ten weeks. Function significantly improved based on the ODI, however pain did not significantly improve using a numeric pain rating scale (NPRS).

O'Sullivan reported on a case series of nine subjects with SIJP with positive ASLR tests and provocation tests who were instructed in TA, IO and pelvic floor $(\mathrm{PF})$ activation in a neutral spine in various positions: supine, sitting, sit to stand, standing, single leg stance and walking. ${ }^{28}$ Outcomes included suboptimal movement of the pelvic floor, diaphragm and suboptimal respiration and disability. These outcomes were discussed earlier under the section of respiration and SIJP.

Two case studies were reported by O'Sullivan to highlight one patient with reduced force closure and one patient with excessive force closure. The female patient with R SIJP had reduced force closure based on a positive ASLR with breath holding and positive provocation testing. She was instructed in TA and pelvic floor activation without breath holding, while maintaining optimal spinal alignment and neutral posture in sitting, standing and lifting. She was also instructed in lunges, squats, aerobic exercise including bicycling and walking and patient education in the vicious pain cycle. At one year after discharge, O'Sullivan reported that she returned to work and to playing handball, however no formal outcome measures were used or reported. The other patient suffered from right more than left SIJP as a result of excessive force closure as measured by a negative ASLR, positive provocation testing and inability to relax her pelvic floor muscles based on an internal exam. This patient was educated in the vicious pain cycle and the need for pelvic floor muscle inhibition. She was instructed in relaxation strategies for muscles and anxiety in sitting, standing and activities of daily living (ADLs) including breathing and rest breaks. She was also referred to a psychologist and at one year, O'Sullivan noted that she experienced "little pain or disability." Again, no formal outcome measures were used or reported.

A case study published by Painter discussed a patient with a positive ASLR and positive provocation testing who was managed with pelvic floor and TA activation during ADLs, 
bridges, lunges, prone exercise over a physioball with alternating upper extremity flexion and lower extremity hip extension, abdominal crunches on a physioball, aquatic exercises and the use of a SIJ belt. The patient was seen for seven visits over three weeks and was reported to have returned to "full activity" with no "stress urinary incontinence" at six weeks. No formal outcome measure was used or reported.

A descriptive report was published by Sasso on 69 subjects with SIJ pain based on symptoms occurring in Fortin's area. ${ }^{68}$ SIJ mobilizations were performed but not described, and strengthening of "muscular stabilizers and abdominals" were reported but not described in any detail. Patient education included instruction by the clinician in proper lifting technique and "activity modification." Outcomes were reported with the use of a survey at two years. Ninety-five percent of subjects reported their outcome as good or excellent and five percent reported their outcome as fair or poor.

The use of a SIJ belt has been used as one part of the intervention for reported patients/subjects with SIJP/SIJD to aid in force closure of the SIJ passively. One study included the investigation of the best placement of the SIJ belt to achieve the greatest decrease in SIJ ligamentous laxity. Placement just below the ASIS was reported as better than at the level of the pubic symphysis. ${ }^{25}$ Damen also investigated how much force was best to decrease SIJ ligamentous laxity by using Doppler Imaging of Vibrations technology to assess ligamentous stiffness. Damen used a strain gauge in the belt for ten females 18-39 years of age without SIJP. Damen reported that either 50 Newtons or 100 Newtons achieved the same benefit. 25

\section{Specific Postural Restoration interventions for a PEC pattern relating to right and/or left SIJP}

Postural Restoration therapeutic exercises (also known as non-manual techniques) can be used for all patients who suffer from pain in their right, left or bilateral SIJs. This chapter will include a description for management of patients who present with bilateral anterior pelvic tilt/PEC pattern followed by a description for management of patients who present with a L AIC pattern and right SIJP followed by those who present with compensation for a L AIC pattern and left SIJP. Clinical reasoning for a patient with a PEC pattern is to restore the ability of the patient to flex their spine and expand their posterior mediastinum as evidenced by the ability to easily touch their toes (without the use of a hamstring lengthening/stretching program) and the ability to fully squat comfortably while breathing. Exercises that may be used include a Standing Unresisted Wall Reach, Standing Resisted Wall Reach, Reverse Door Squat (with or without the assistance of a pole to hold on too) or a Wall Short Seated Reach. (Figures 9-12) The Unresisted Wall Reach may be enough to achieve spinal flexion and posterior mediastinum expansion, however some patients may need more abdominal recruitment to achieve the results, therefore the Resisted Wall Reach may be more beneficial. Some patients may have pain in their knee/s or back and therefore are unable to do either of the standing wall reach exercises or the squat exercise. In that case, the Wall Short Seated Reach may be a good option. Once the patient's sagittal plane motion and ability is restored, the patient is managed for the underlying L AIC pattern depending on the side of involvement. 


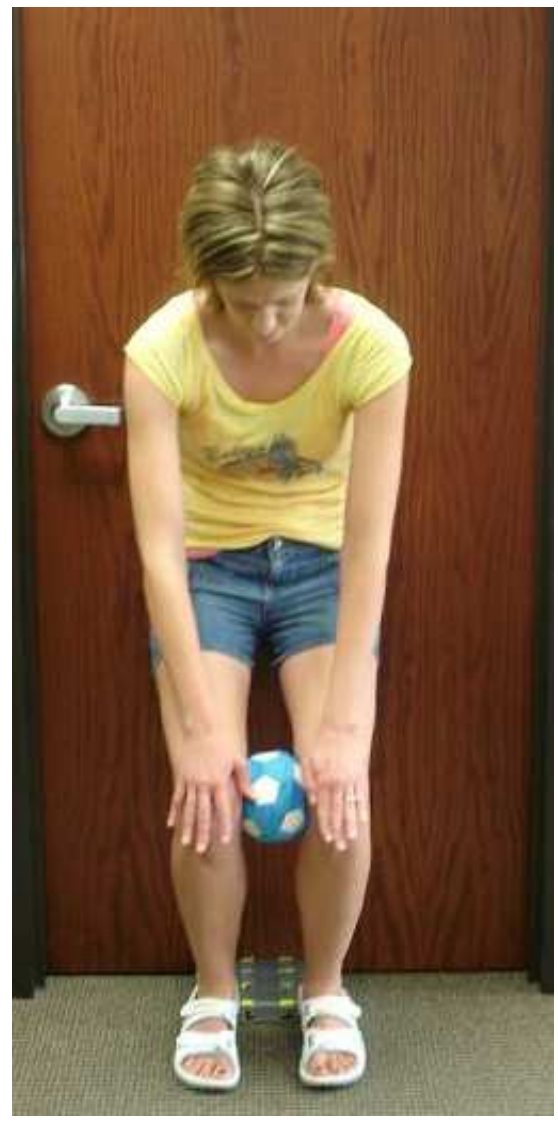

Fig. 9. Standing Un-resisted Wall Reach

1. Stand facing away from a wall and place your heels 7-10 inches away from the wall.

2. Stand up straight with a ball between your knees and feet shoulder width apart.

3. Bring your arms out in front of you as you round out your back, performing a pelvic tilt so your mid-back down is flat on the wall.

4. Squat down slightly as you squeeze the ball.

5. Keeping your mid-back down on the wall, inhale through your nose.

6. As you exhale through your mouth, reach your arms forward so your upper back comes off the wall (mid-back down should stay flat on the wall).

7. Hold your arms steadily in this position (reach), as you inhale through your nose again and expand your upper back (feel a stretch in your upper back).

8. Exhale and reach further forward.

9. Repeat this breathing sequence for $4-5$ deep breaths.

10. Slowly stand up by pushing through your heels and slide up the wall, keeping your mid-back down on the wall.

11. Relax and repeat 4 more times.

Copyright (C) Postural Restoration Institute ${ }^{\mathrm{TM}}$ used with permission, www.posturalrestoration.com 


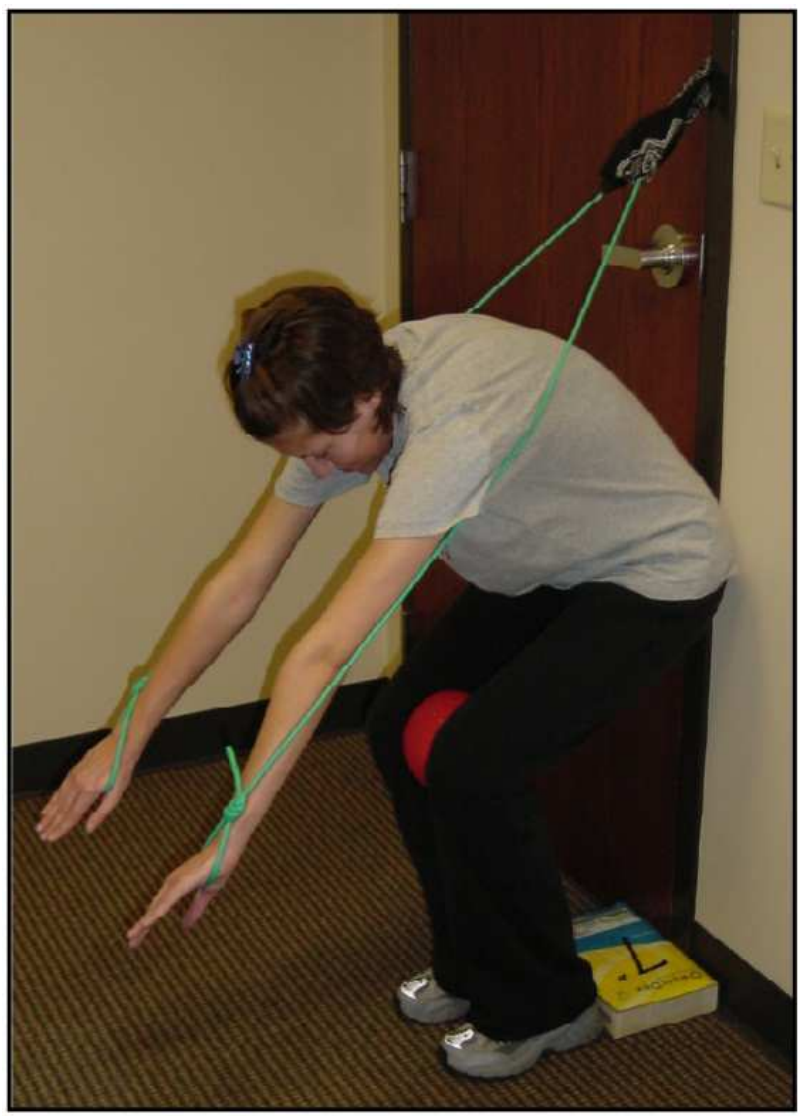

Fig. 10. Standing Resisted Wall Reach

1. Place tubing securely in door slightly below shoulder level.

2. Stand with your heels 7-10 inches away from the wall.

3. Stand up straight with a ball between your knees and feet lined up with each other.

4. Place your hands through the loops of the tubing with your palms facing down.

5. Straighten your arms out in front of you and round your back, engaging your abdominals.

6. Once you can feel your abdominals working begin to squat as you squeeze the ball.

7. Squat down until your bottom touches the wall (do not fall back into wall).

8. Inhale through your nose.

9. As you exhale through your mouth reach forward and downward as your back stays rounded.

10. Hold arms steadily in this position as you inhale again and expand your back.

11. Exhale and reach forward further with your arms.

12. Complete 2 more breaths in and out reaching further each time you exhale.

13. Stand up while keeping arms straight, back rounded, abdominals and inner thigh muscles engaged.

14. Relax and repeat 4 more times.

Copyright $\left(\right.$ C Postural Restoration Institute ${ }^{\mathrm{TM}}$ used with permission, www.posturalrestoration.com 


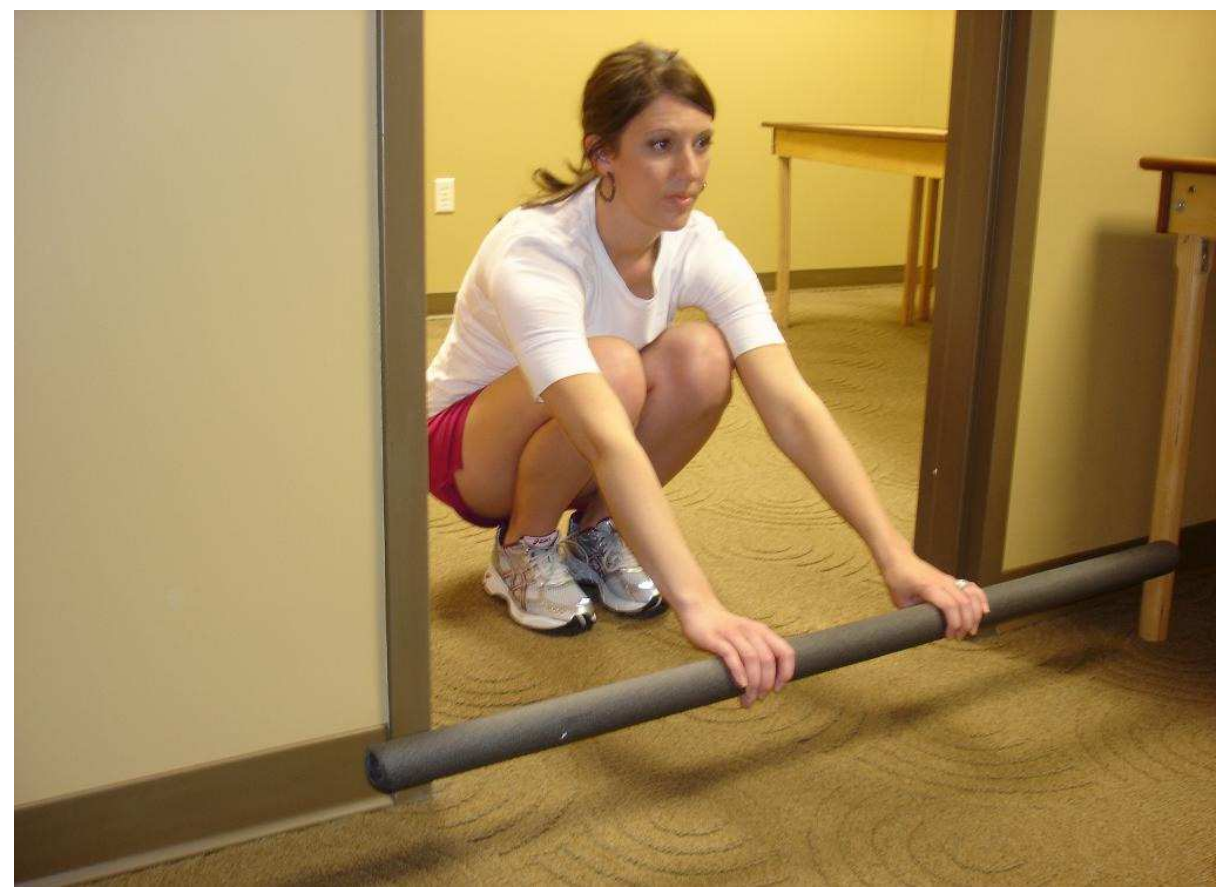

Fig. 11. Reverse Door Squat

1. Stand in front of an open doorway and place a wooden pole in front of the door frame at or below standing knee height.

2. Hold onto the pole and find the best functional squat position (bottom of pelvis to heel cords) while keeping your heels down and knees inside your elbows. You may need to stand back up and re-position your feet so you can get your bottom down as far as allowed.

3. Once you have positioned yourself in the most optimal squat position, take a deep breath in through your nose and fill the back of your chest wall with air while keeping your eyes up or level with the floor. Exhale through your mouth as you lean back until all your air is out. Repeat this sequence of inhalation and exhalation 3 to 4 more times always allowing your heel cords, front of your thighs/knees and your back muscles to relax and stretch.

4. After the fourth breath in, exhale and begin to stand up pushing down through your heels and keeping your back rounded while sliding the pole up the door frame as necessary to assist you in coming up.

5. Lower the pole and repeat the process 4 more times.

6. The goal is to perform the first 3 steps above with the pole at the level of your ankle, with your elbows straight, with your knees in your chest and with the bottom of your pelvis on your heel cords (PRI Squat Level Four or Five).

Once you've achieved the above goal, repeat the first three steps. After the fourth breathe in, reach forward with your hands as you exhale so that the pole loses contact with the door frame. As you exhale also begin to stand up pushing through your heels and continuing to reach forward so that the pole doesn't touch the door frame.

Copyright $\left(C\right.$ Postural Restoration Institute ${ }^{\mathrm{TM}}$ used with permission, www.posturalrestoration.com 


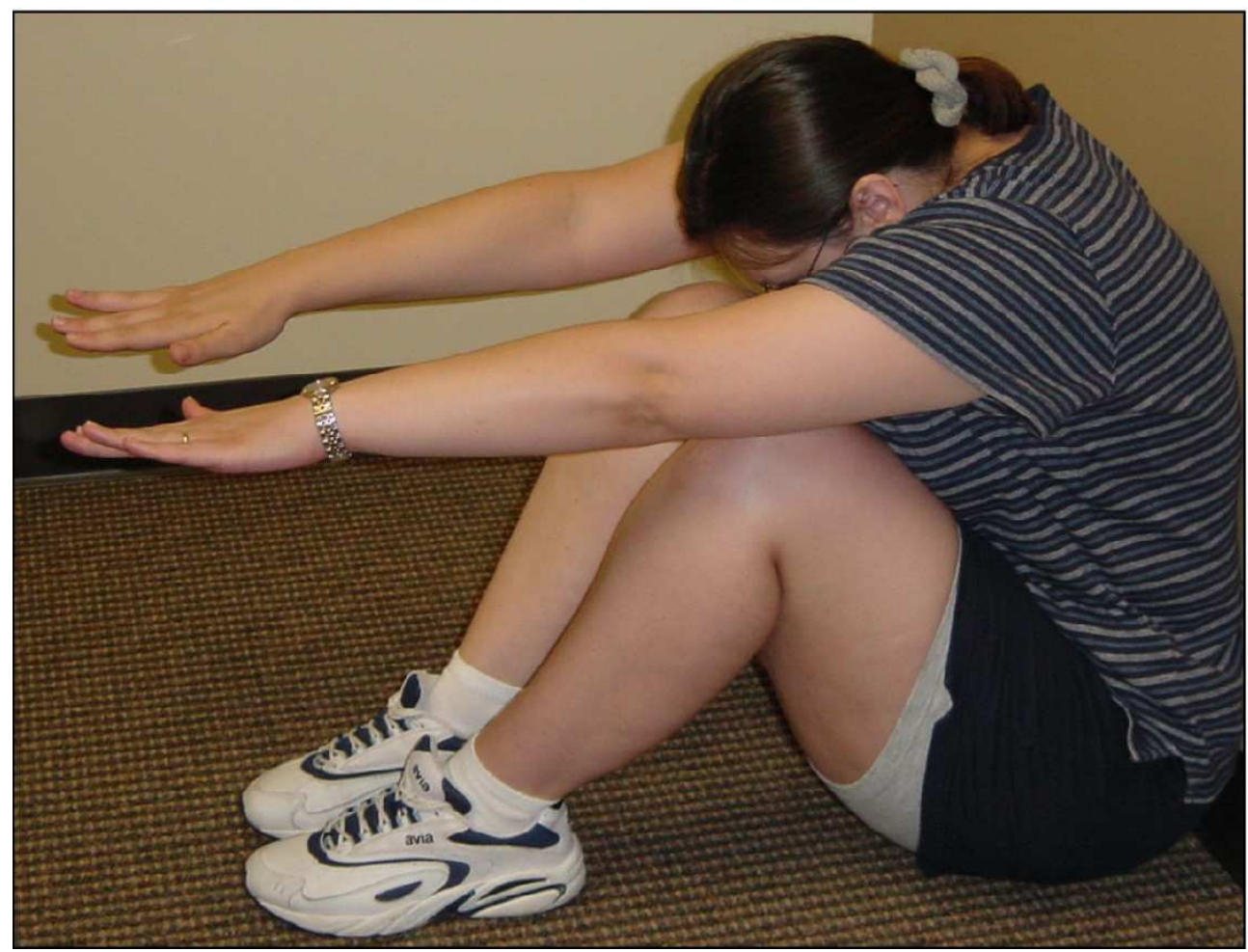

\section{Fig. 12. Wall Short Seated Reach}

1. Sit on the ground with your mid to low back flat against a wall and legs straight out in front of you.

2. Bring your knees as close to your chest as possible by bending your legs one at a time. Keep your knees together and feet slightly apart. Do not allow your legs to rotate outward.

3. Inhale through your nose.

4. Keeping your back on the wall from bra-line to belt-line, slowly exhale through your mouth and reach forward with both arms. Your arms may rest on your knees. Pause 3 seconds.

5. Maintaining the position, inhale again through your nose and concentrate on filling the back of your chest wall with air.

6. Exhale and reach forward further with your arms.

7. Continue in this manner for 4 breaths in and 3 breaths out pausing 3 seconds before each inhalation.

8. Relax and repeat 4 more times.

Copyright (C) Postural Restoration Institute ${ }^{\mathrm{TM}}$ used with permission, www.posturalrestoration.com 


\subsection{Right sacroiliac joint pain/dysfunction related to a left anterior interior chain pattern}

Clinical reasoning used by clinicians trained in Postural Restoration to manage right $\mathrm{SIJP} /$ instability, is to optimize lumbar-pelvic-femoral position and train the patient to maintain it. This is achieved most commonly by therapeutic exercise instruction/prescription such as right GM activation in the transverse plane that emphasizes normal breathing through the exercise (to avoid breath holding/splinting of the diaphragm) and patient education in positional guidelines during activities of daily living (ADLs). The positional guidelines attempt to oppose the L AIC pattern (e.g. maintain weight over left leg, maintain desired hip positions) during common activities such as sit to stand, sleeping, standing etc. (Figures 13-15)

Therapeutic exercises that activate specific muscles on specific sides of the body and train a patient in different phases of gait to achieve for example, single leg stance control are often used. Exercises with the patient in a sidelying or supine position are usually done initially until motor control with the correct muscles is achieved. After the patient demonstrates mastery of correct position and muscle activation, exercises may be advanced to a standing position. These exercises are also designed for the patient to be able to eventually maintain stability without compensation. SIJP occurring on the right side is thought to occur because of too much motion across the posterior right SIJ. Based on the L AIC pattern, the right hip is often positioned in IR and adduction. Therefore, to achieve optimal lumbar-pelvic-femoral position the goal would be to achieve right hip ER, specifically right acetabulum over femur (AF) ER with concomitant left hip IR, specifically acetabulum motion over the femoral head (L AF IR). The right GM can be considered an important muscle for both form and force closure. The right GM can correct right hip IR in a transverse plane via its action as a powerful external rotator which may contribute to repositioning the sacrum from a position of orientation in right rotation toward neutral (i.e. form closure). The GM is also an effective muscle to restore force closure across the SIJ. There are currently no therapeutic exercises to activate the GM in the transverse plane in published literature relating to management of patients with SIJP outside of those related to Postural Restoration and developed by Ron Hruska PT.

The GM can be activated in the transverse plane in several patient positions: sidelying, supine hooklying and supine with the hips and knees at 90 degrees. In a sidelying position, the GM can be activated in the transverse plane against gravity with or without a band (fit loop) for resistance. (Figure 16) Sagittal plane position of the trunk/spine can be monitored to avoid excessive lumbar lordosis and the feet can rest over a small bolster and press against a wall to gain distal stability and to serve as a fulcrum for the motion and place the right hip into more IR which allows for more ER ROM during the movement of the right leg during the exercise. In a supine position, the right GM is again activated in the transverse plane usually with resistance (fit loop) around both femurs. (Figure 17) To avoid excessive lordosis or over activity of paraspinals the patient moves into a posterior pelvic tilt first with an exhalation and maintains that position throughout the exercise. The left hip can actively be moved into L AF IR which puts both the left and right hips into the desired positions based on the L AIC pattern. R AF ER is not only the desired position; it also shortens the GM positionally before further shortening through FA ER against the resistance of the fit loop. The supine 90/90 position is essentially the same as the supine hooklying position as the right GM is activated in the transverse plane against resistance after the patient moves into $\mathrm{L}$ AF IR and R AF ER with stability offered at the feet by the wall. (Figure 18) 


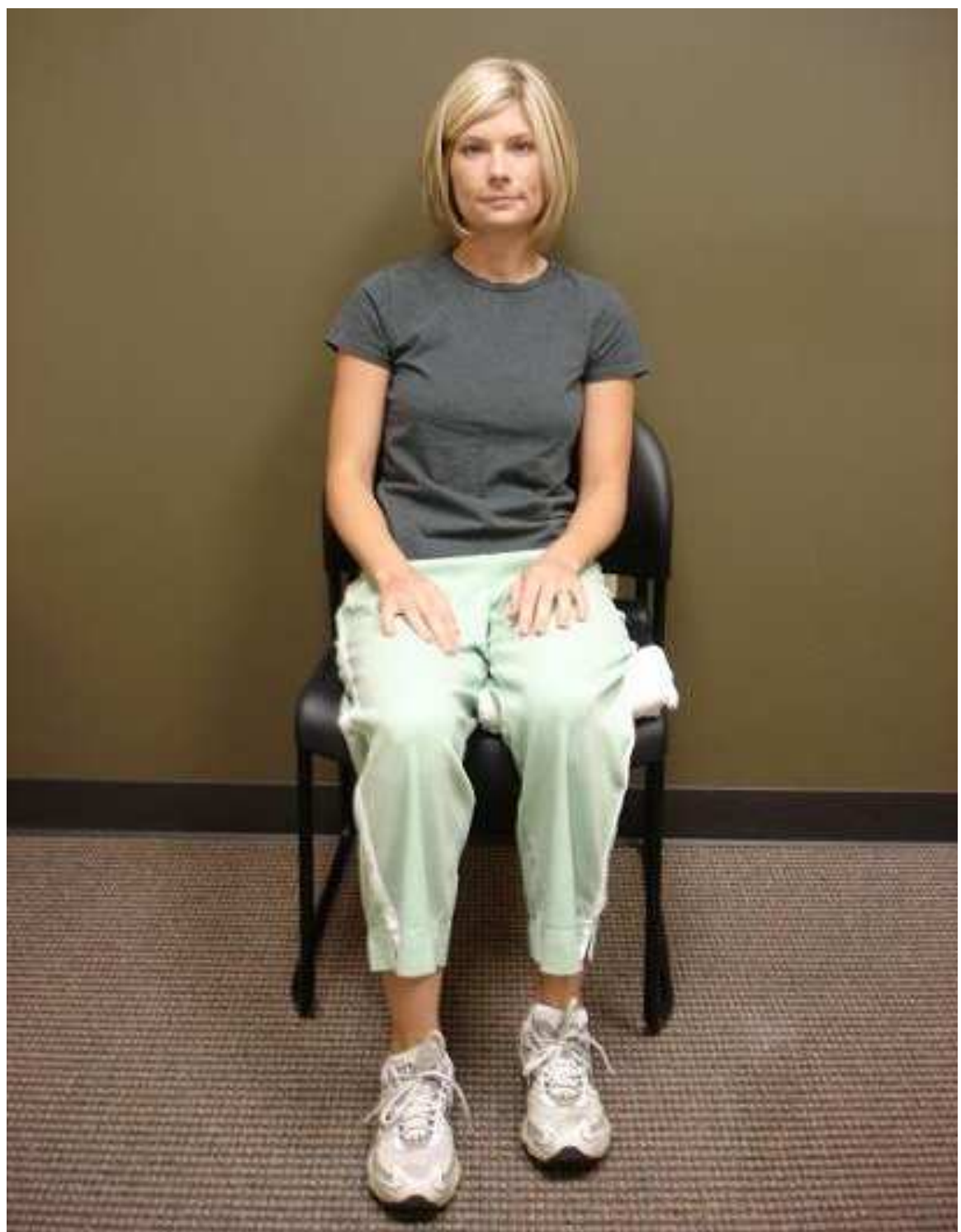

Fig. 13. Positional recommendations for sitting in a left hip (acetabulum over femur) internal rotation (L AF IR) position

When in a seated position attempt to keep your trunk rounded and your knees at or above hip level.

For increased comfort place a small bolster underneath your left thigh and shift your left knee back.

Copyright $(C)$ Postural Restoration Institute ${ }^{\mathrm{TM}}$ used with permission, www.posturalrestoration.com 


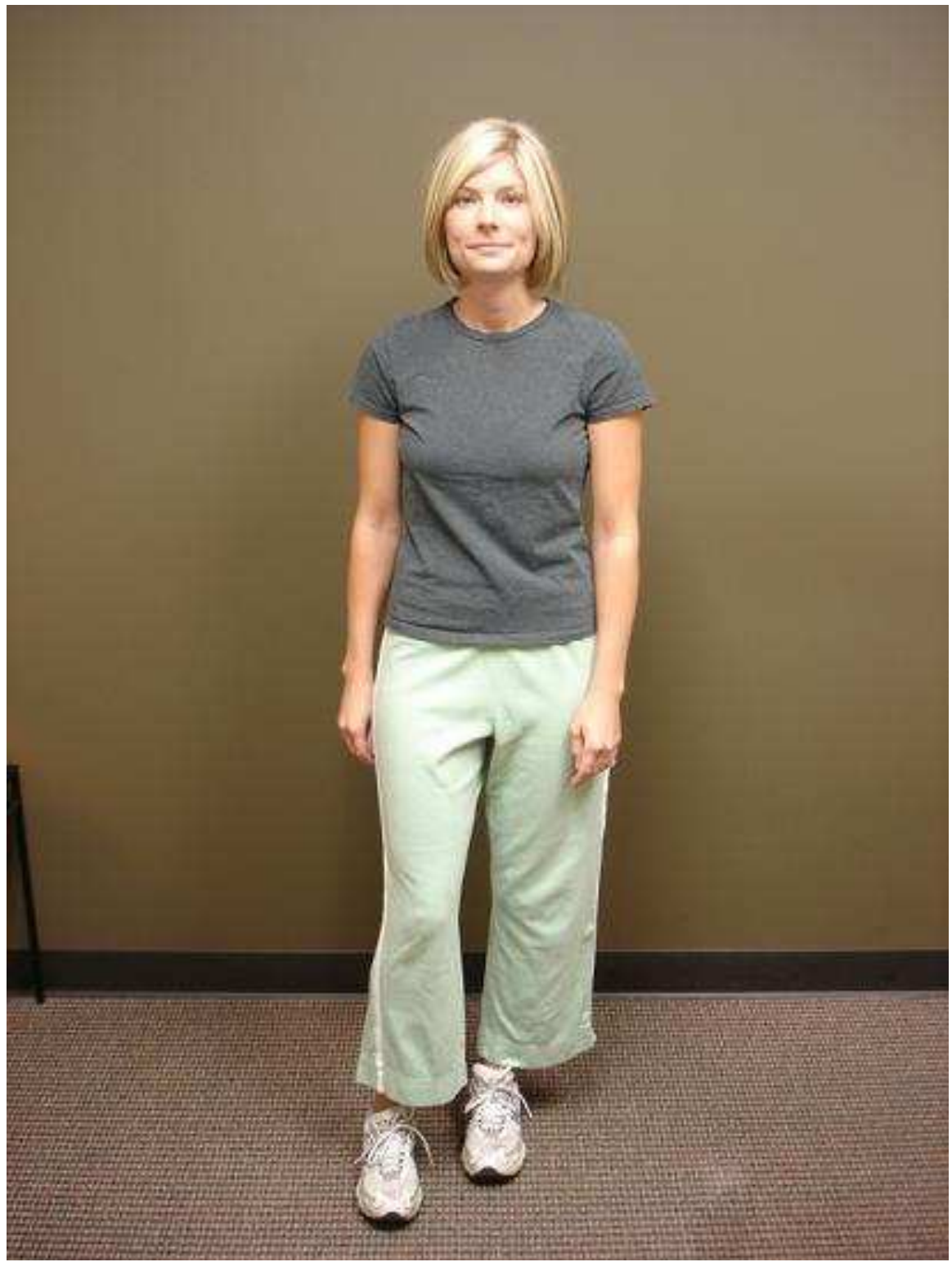

Fig. 14. Positional recommendation in a standing left hip (acetabulum over femur) internal rotation (L AF IR) position with center of gravity shifted to the left.

When standing, place your right foot ahead of your left and attempt to keep your body weight shifted to the left.

Copyright (C) Postural Restoration Institute ${ }^{\mathrm{TM}}$ used with permission, www.posturalrestoration.com 


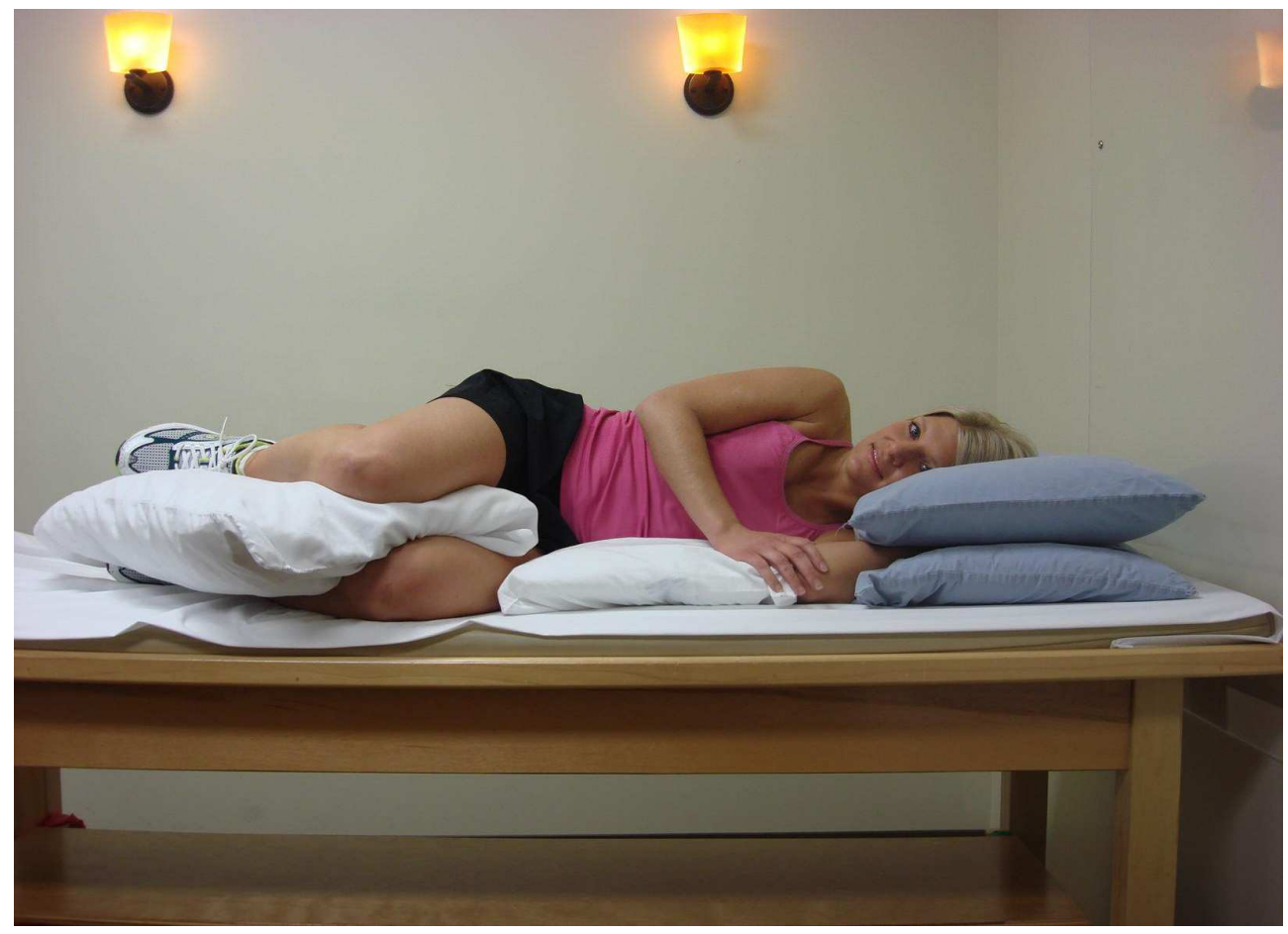

Fig. 15. Positional recommendations for sleeping with pillow support and L AF IR Place a pillow between your legs when on either side. Place a pillow under your left side when lying on your left side. Use one-two pillows under your head to keep your head and neck relaxed.

Copyright (C) Postural Restoration Institute ${ }^{\mathrm{TM}}$ used with permission, www.posturalrestoration.com 


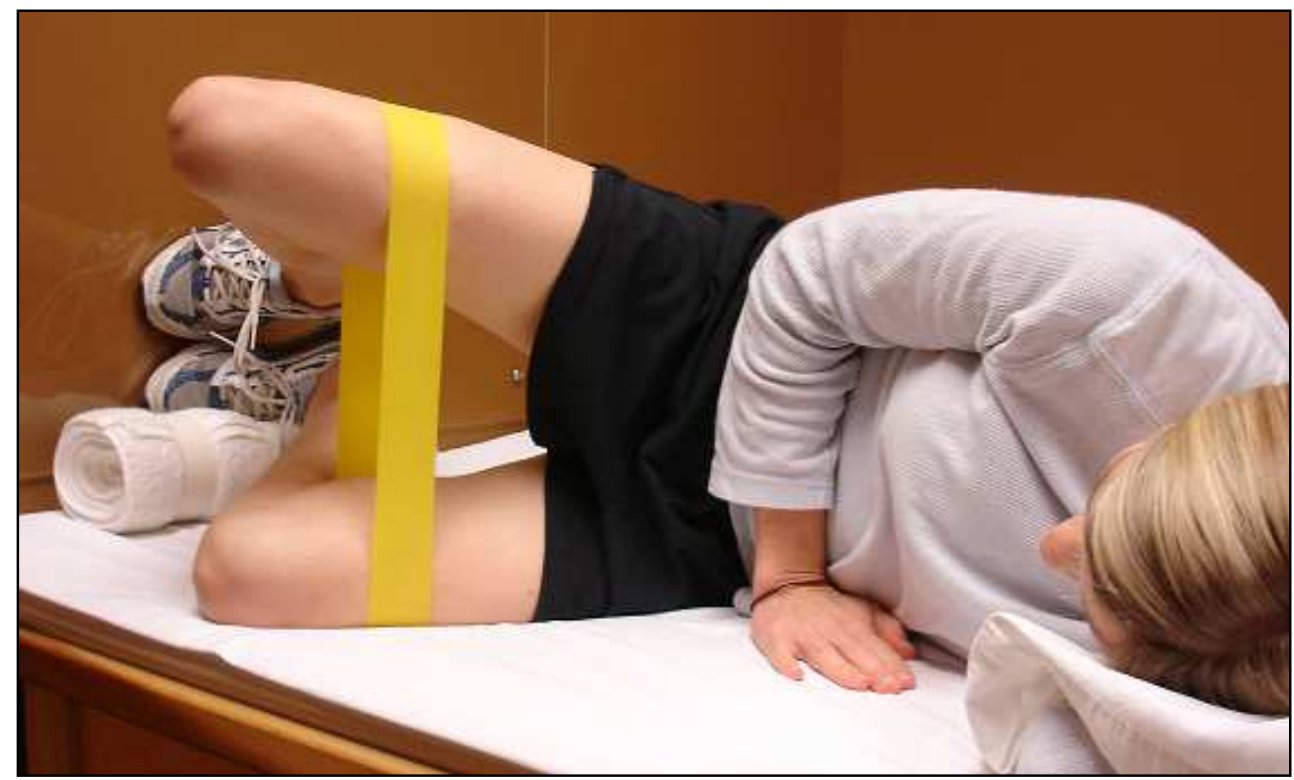

Fig. 16. Left Sidelying Right Glute Max

1. Lie on your left side with your hips and knees bent at a 60-90 degree angle.

2. Place your ankles on top of a 3-5 inch bolster and place your feet firmly on a wall.

3. Place tubing around both thighs slightly above your knees.

4. Shift your right hip forward until you feel a slight stretch or pull in your left outside hip.

5. Keeping your toes on the wall, raise your right knee keeping it shifted forward. You should feel your right outside hip engage.

6. Hold this position while you take 4-5 deep breaths in through your nose and out through your mouth.

7. Relax and repeat 4 more times.

Copyright (C) Postural Restoration Institute ${ }^{\mathrm{TM}}$ used with permission, www.posturalrestoration.com 

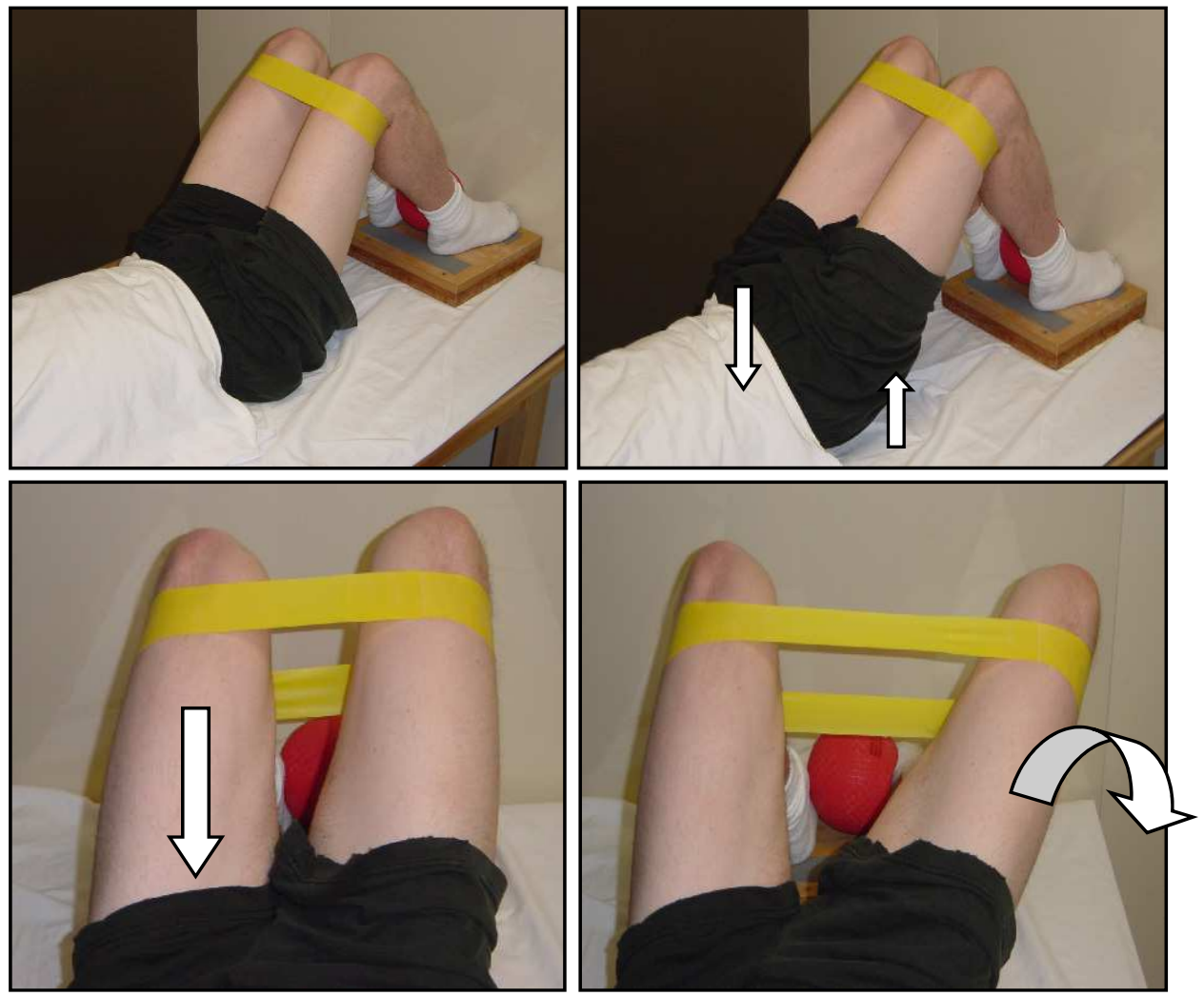

Fig. 17. Supine Hooklying Right Glute Max with R AF ER

1. Lie on your back and place your feet on a 2-inch block against the wall.

2. Place a band around your knees and a ball between your ankles.

3. Inhale through your nose and exhale through your mouth performing a pelvic tilt so that your tailbone is raised slightly off the mat. Keep your back flat on the mat.

4. Shift your left knee down. You should feel your left inner thigh engage.

5. Turn your right leg out. You should feel your right outside hip engage.

6. Hold this position while you take 4-5 breaths in through your nose and out through your mouth.

7. Relax and repeat 4 more times.

Copyright $\left(C\right.$ Postural Restoration Institute ${ }^{\mathrm{TM}}$ used with permission, www.posturalrestoration.com 

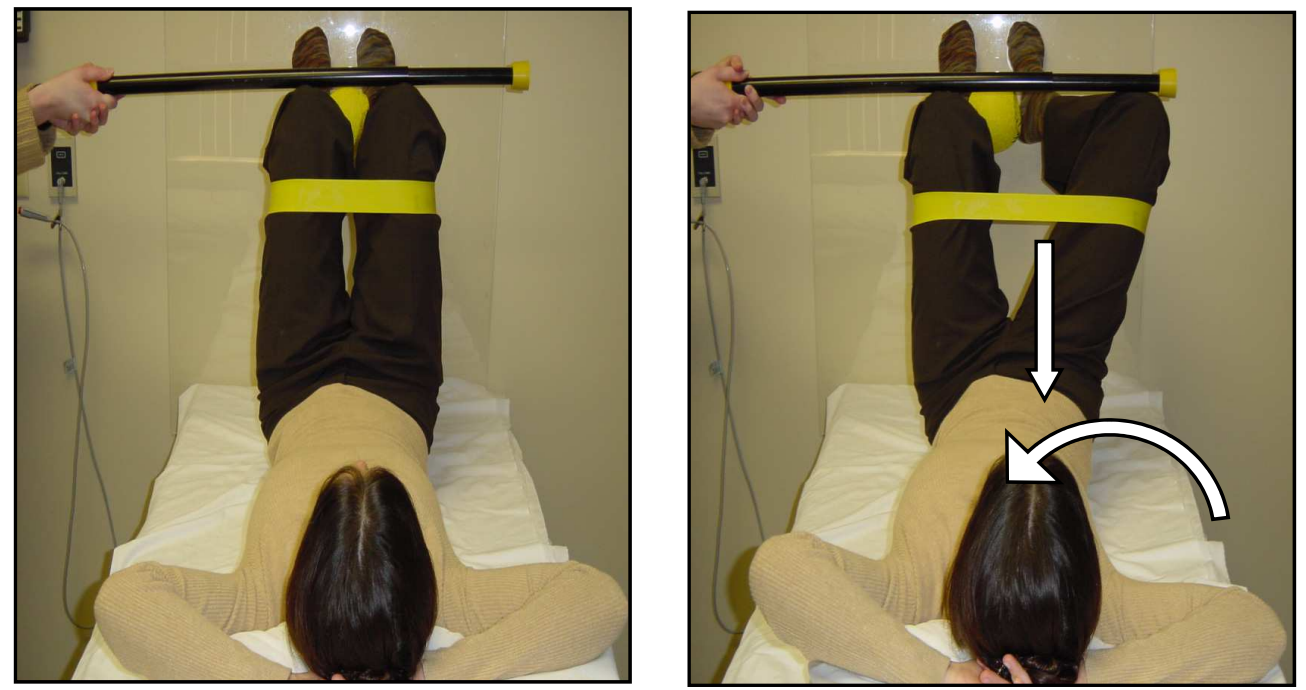

Fig. 18. Supine Right Glute Max with Right AF ER

1. Lie on your back with your feet on a wall and your knees and hips bent at a 90-degree angle.

2. Place tubing around your thighs (just below your knees) and a 4-5 inch ball between your ankles.

3. Inhale through your nose and exhale through your mouth performing a pelvic tilt so that your tailbone is raised slightly off the mat. Keep your back flat on the mat.

4. Maintaining a pelvic tilt, shift your left knee down as your left pelvis drops and your right pelvis raises and turns to the left. You should feel the muscles on the outside of your right hip engage.

5. Squeeze your left ankle into the ball feeling your left inner thigh engage.

6. Attempt to lift left heel off of the wall.

7. Hold position while you take 4-5 deep breaths in through your nose and out through your mouth. Relax and repeat 4 more times.

\section{Copyright (C) Postural Restoration Institute ${ }^{\mathrm{TM}}$ used with permission} www.posturalrestoration.com

The L AIC pattern commonly involves over activity and possibly shortness of the right adductors which contribute to or are a result of the right hip IR/adduction seen with a L AIC pattern. If it is determined by the clinician that the adductors are over active/short a therapeutic exercise to inhibit/lengthen the right adductors may be prescribed. (Figure 19) An example of an upright exercise that facilitates activation of the R GM and a left hip position of L AF IR is the Single Leg Wall Left AF IR with Right Glute Max. This exercise is developed to oppose the typical L AIC pattern via activation of the R GM in a transverse plane, while weight bearing on the left leg in a hip position of L AF IR. (Figure 20) To summarize, management of R SIJP associated with a L AIC pattern includes a focus on $R$ GM activation in a transverse plane with desired hip positions (R AF ER and L AF IR) that oppose the positions commonly seen in the L AIC pattern, and right adductor inhibition/lengthening as needed. 


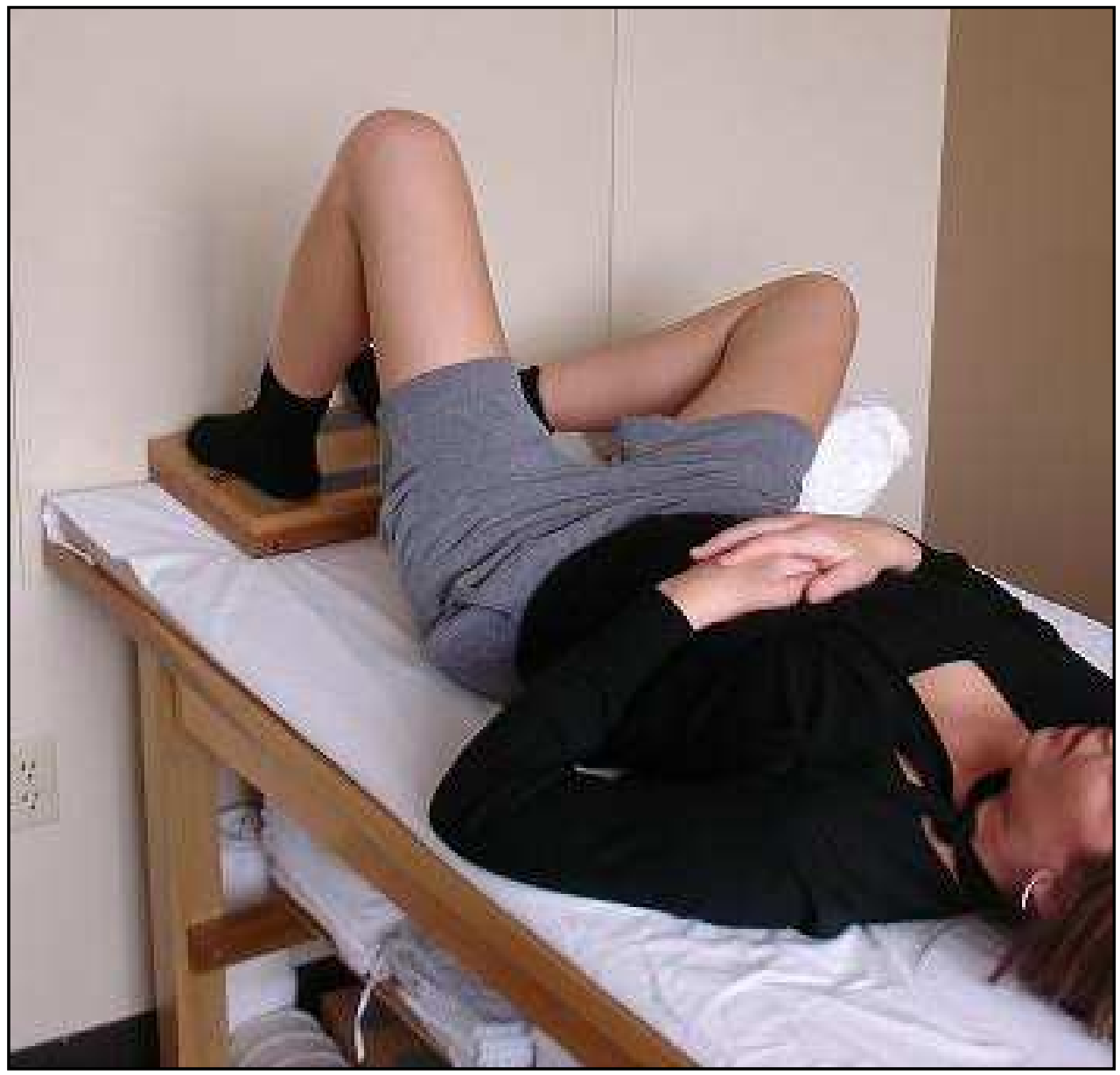

Fig. 19. Supine Hooklying Adductor Magnus Inhibition

1. Lie on your back with your feet on a 2-inch block.

2. Place a bolster or pillow of appropriate size on your right side.

3. Inhale through your nose and exhale through your mouth performing a pelvic tilt so that your tailbone is raised slightly off the mat. Keep your back flat on the mat.

4. Maintaining a pelvic tilt, let your right knee lower to the side until it reaches the bolster or pillows. You should feel a stretch across your right inner thigh.

5. Hold this position while you take 4-5 deep breaths in through your nose and out through your mouth.

6. Let your left knee drop down to meet your right.

7. Keeping both legs together, slowly bring them upright as one unit.

8. Relax and repeat 4 more times.

Copyright (C) Postural Restoration Institute ${ }^{\mathrm{TM}}$ used with permission, www.posturalrestoration.com. 


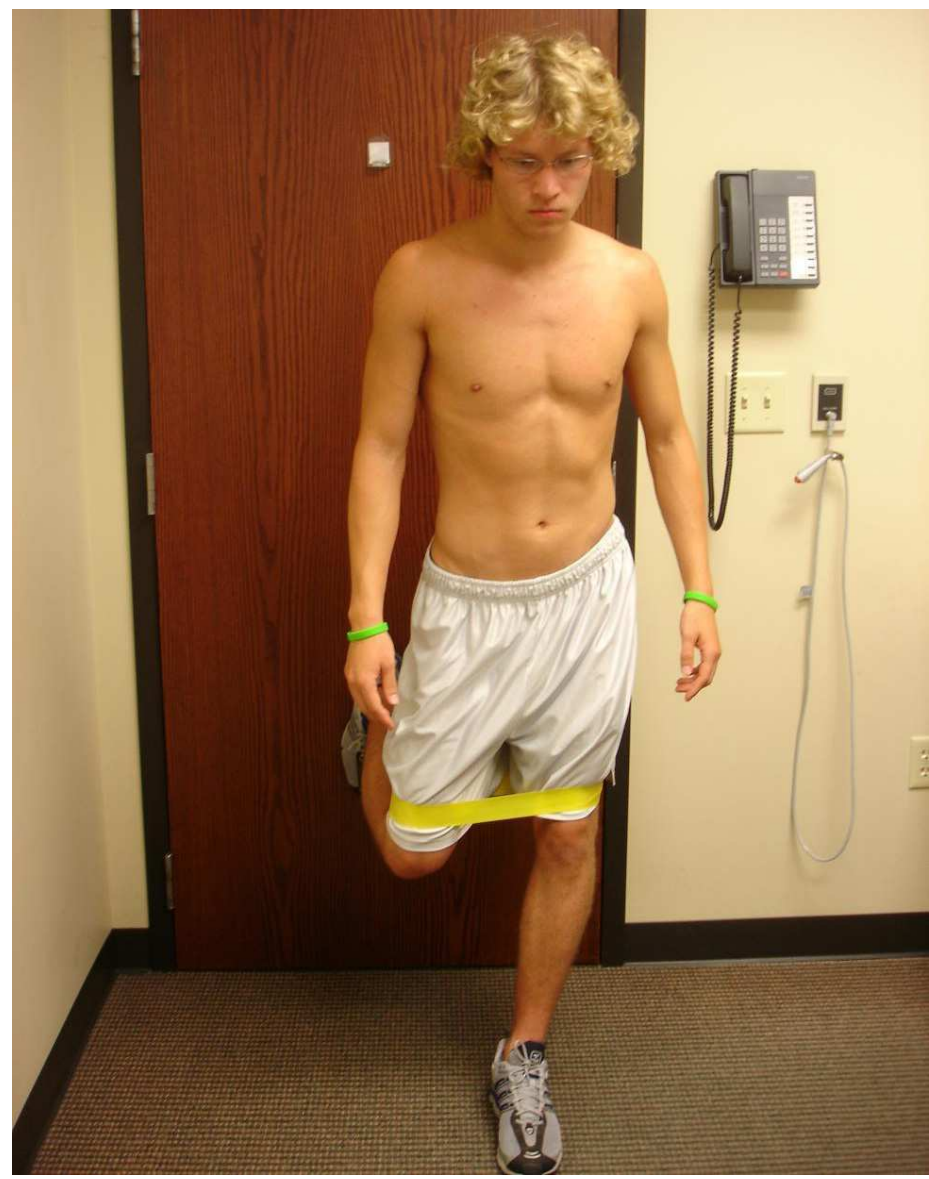

Fig. 20. Single Leg Wall Left AF IR with Right Glute Max

1. Place a band around both your legs slightly above your knees.

2. Stand facing away from a door. Place your right foot flat against the door by bending your right knee.

3. Align your knees together by adjusting your body's position and distance from the door.

4. Shift your right knee down towards the floor. Your right knee will be below the level of your left. You should feel your left outer hip engage.

5. While standing on your left leg, push your right foot firmly into the door as you maintain steady control and balance of your trunk.

6. Turn your right knee outward. You should feel your right outside hip engage along with your left outside hip.

7. Balance in this position while you take $4-5$ deep breaths in through your nose and out through your mouth.

8. Relax and repeat 4 more times.

Copyright $\left(\subset\right.$ Postural Restoration Institute ${ }^{\mathrm{TM}}$ used with permission www.posturalrestoration.com 


\subsection{Left sacroiliac joint pain/dysfunction related to a left anterior interior chain pattern}

Clinical reasoning for L SIJP/SIJD related to a L AIC pattern is similar to that of the R SIJ but rather than the strongest focus being on the R GM, the focus is on addressing the left hip/femur ER that is thought to occur as a result of compensation for the asymmetrical pelvic position. Left hip IR may be a challenging position for a patient to achieve if they have over active/strong and perhaps short left hip external rotator muscles holding them into hip ER and strong/over active right adductors holding them in right IR or a position of COG shifted right. Patients however require left hip IR for early stance phase of gait which requires them to shift their left acetabulum over the left femoral head. Compensation for the inability to get L AF IR may result in too much motion occurring in the L SIJ which may contribute to L SIJ instability. Intervention then would focus on training the left hip to IR via motion of the left acetabulum to move over the left femur (AF IR) and to activate left hip IR muscle such as the anterior gluteus medius (ant glut med) and the ischiocondylar (IC) portion of the left adductor magnus (AM). There are no known published articles relating to management of patients with SIJP that describe exercises or the importance of exercises that activate the adductors or anterior gluteus medius with the exception of one published case study that used Postural Restoration exercises. ${ }^{47}$ Additionally, there is one poster presented and abstract published including a case series of patients with SIJP where Postural Restoration exercises were prescribed.69,70

If the pattern has been present for a long time, the $\mathrm{L}$ posterior capsule/ischiofemoral ligament may become adaptively short. This would require stretching/lengthening of the posterior hip ligament to allow for the L AF IR position and proper seating of the left femoral head into the acetabulum. An exercise called the Right Sidelying Left Adductor Pull Back ${ }^{48}$ done in right sidelying facilitates the desired hip positions (L AF IR and concomitant R AF ER), stretches the left ischiofemoral ligament/posterior capsule and activates left hip IR muscle i.e. adductors. (Figure 21) Resistance can be used to facilitate recruitment of the left hamstrings/adductors if desired, however that requires an individual to hold the band and may not be feasible for many patients.

A Left Sidelying Knee to Knee exercise ${ }^{46-48}$ takes advantage of gravity when activating left hip IR muscles (adductor magnus and anterior glut med) while also activating the R GM in a transverse plane to anchor the left hemipelvis back to the $\mathrm{L}$ and discourages over activity of paraspinals and an excessive lordotic position. (Figure 22) Another exercise to activate the left anterior gluteus medius against resistance while having the hip internally rotate (femur on acetabulum or "FA IR") is the Supine Hooklying Right Glute Max with Left Glute Med. (Figure 23) The Left Sidelying Left Flexed Adduction with concomitant Right Lowered Extended Abduction ${ }^{71}$ exercise integrates L abdominal wall activation along with L hip IR muscle (ant glut med and IC AM) with right GM and glut med in a position of right hip and knee extension as used in a R stance phase of gait. (Figure 24) This exercise may help to neuromuscularly reeducate the patient's left leg to rotate internally rather than externally while in a right stance phase of gait. Lastly, an exercise designed to activate the left internal oblique and transverse abdominus while also activating the right GM and L IC AM in a position of left stance phase of gait is the Left Sidelying IO/TA and Left Adductor with Right Glute Max. (Figure 25) This exercise may help to neuromuscularly reeducate the patient's left leg to rotate internally rather than externally while in a left stance phase of gait, while keeping the COG shifted left and the abdominal wall muscles on. 


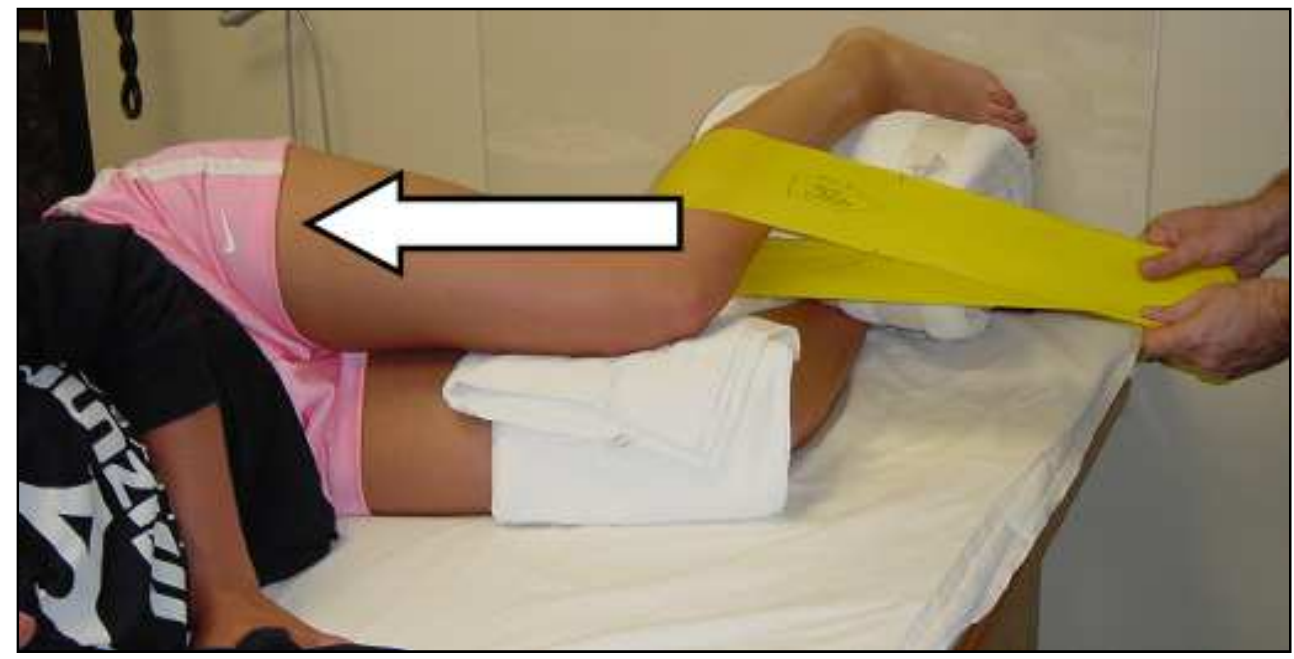

\section{Fig. 21. Right Sidelying Left Adductor Pull Back}

1. Lie on your right side with your toes on a wall, ankles and knees together and your back rounded. Place a pillow under your head and keep back and neck relaxed.

2. Place a bolster of appropriate size between your feet and a towel between your knees. Your left knee should be lower than your left hip and ankle.

3. Place tubing around your left leg just below your knee for resistance. Have another person hold the other end to provide resistance.

4. Push your bottom foot into wall.

5. Begin by inhaling slowly through your nose as you "pull back" your left leg.

6. Exhale through your mouth as you squeeze your left knee down into the towel for 3 seconds.

7. Inhale again as you "pull back" your left leg further. You should begin to feel your left inner thigh engage.

8. Exhale and squeeze your left knee down.

9. Continue the sequence until you have completed 4-5 breaths in and out. Attempt to pull back your left leg further each time you inhale.

10. Relax your knees back to the starting position and repeat the sequence 4 more times.

Copyright $\left(C\right.$ Postural Restoration Institute ${ }^{\mathrm{TM}}$ used with permission, www.posturalrestoration.com 


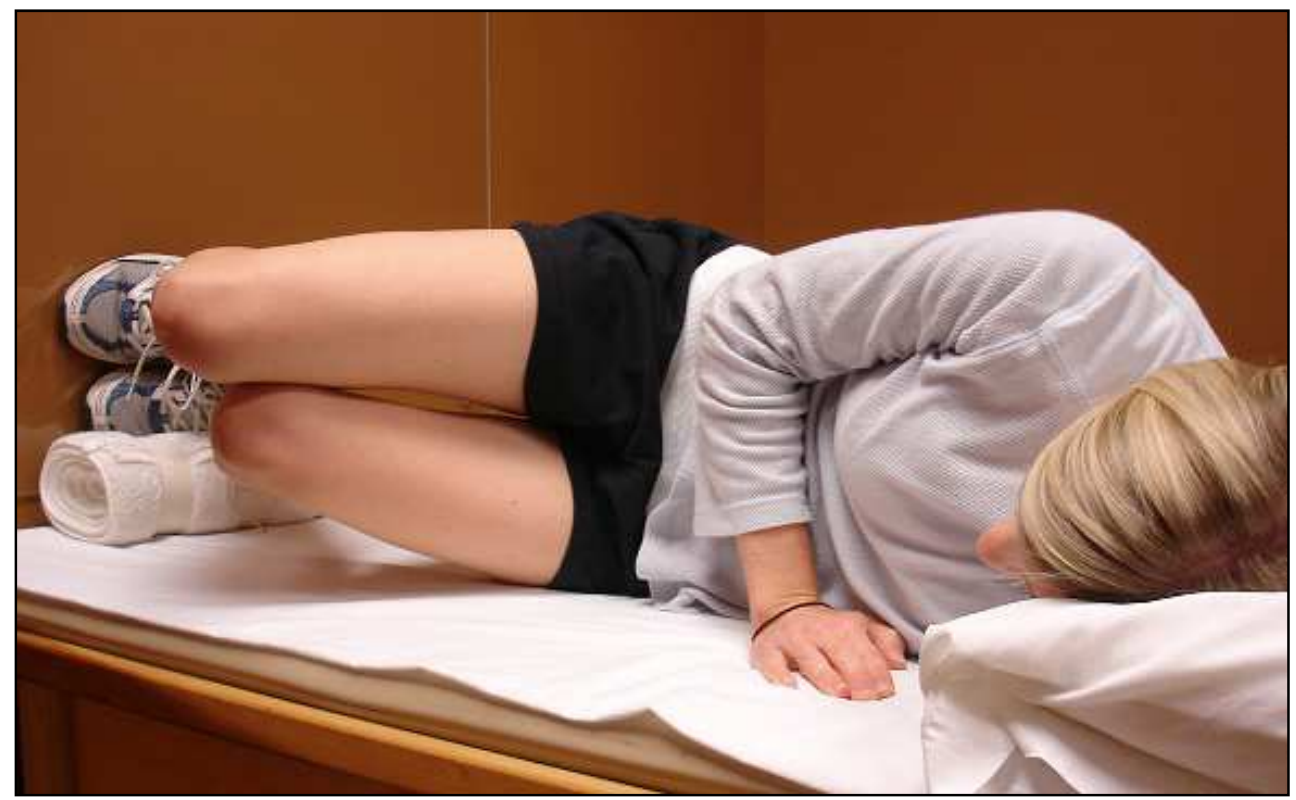

Fig. 22. Left Sidelying Knee to Knee

1. Lie on your left side with your toes on the wall, knees together and back rounded.

2. Place a bolster underneath your ankles.

3. Push your bottom toes into the wall.

4. Lift up or turn "out" your upper thigh.

5. Then lift up or turn "in" your lower thigh. You should feel your left inner thigh engage.

6. Hold your legs together while you take $4-5$ deep breaths in through your nose and out through your mouth.

7. Relax and repeat 4 more times.

Copyright (C) Postural Restoration Institute ${ }^{\mathrm{TM}}$ used with permission, www.posturalrestoration.com 


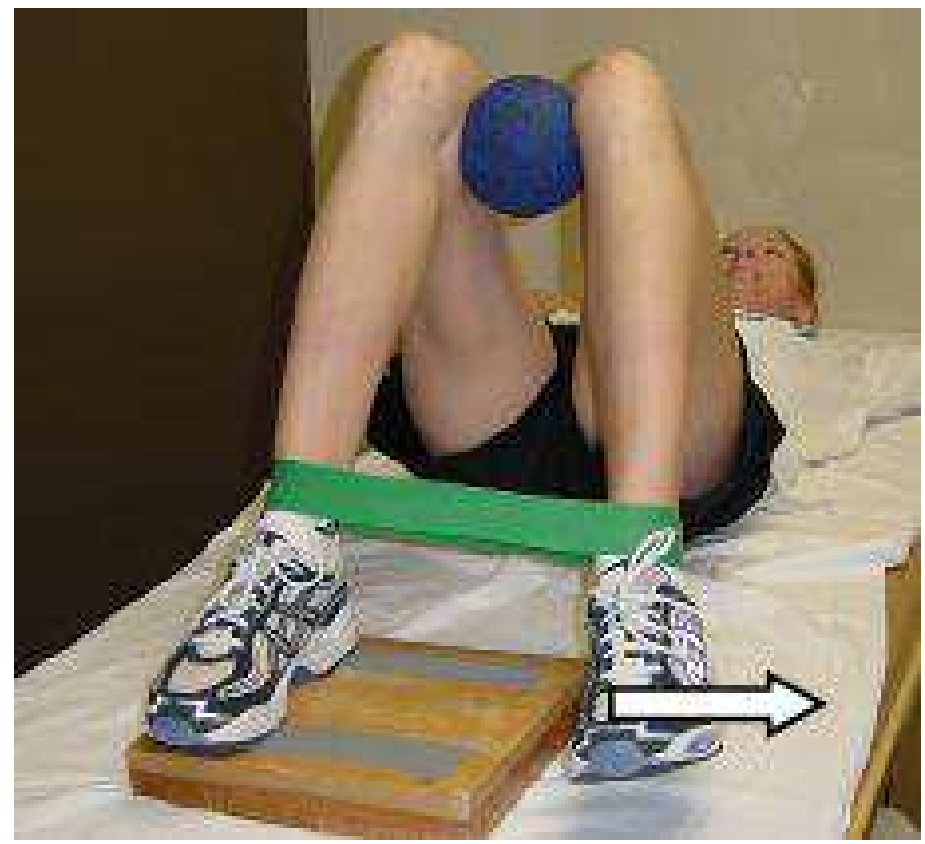

Fig. 23. Supine Hooklying Right Glute Max with Left Glute Med

1. Lie on your back with your feet on a 2-inch block and your knees bent.

2. Place a ball between your knees and a band around your ankles.

3. Inhale through your nose and then exhale through your mouth performing a pelvic tilt so that your tailbone is raised slightly off the mat. Keep your back flat on the mat.

4. Shift your right knee down towards you so that your right knee is slightly below your left. You should feel your right inner thigh engage.

5. Now lift your left foot off of the block. You should feel the back of your right leg and outside hip engage.

6. With your left foot off of the block turn your left ankle out to the side. You should feel your left outer hip engage.

7. Hold this position while you take 4-5 deep breaths in through your nose and out through your mouth.

8. Relax and repeat 4 more times.

Copyright $\left(C\right.$ Postural Restoration Institute ${ }^{\mathrm{TM}}$ used with permission, www.posturalrestoration.com 


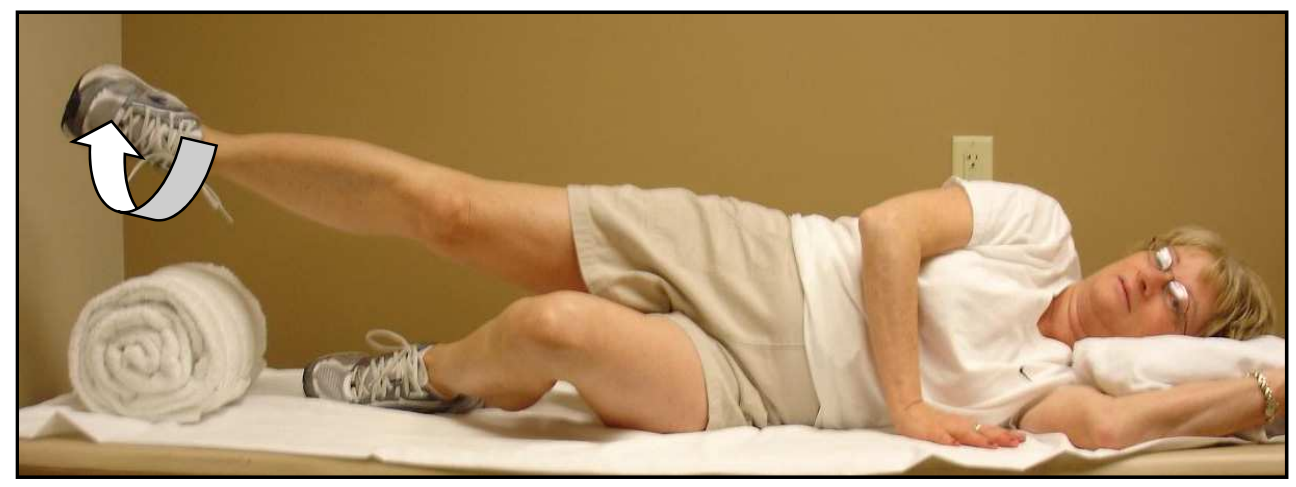

Fig. 24. Left Sidelying Left Flexed Adduction with Concomitant Right Lowered Extended Abduction

1. Lie on your left side and place a 2-3 inch bolster under your left abdominal wall and 1-2 pillows under your head so that your neck is slightly side bent to the right.

2. Place a bolster of appropriate size under your right ankle so that your right leg is level with your trunk and bend your left knee.

3. Inhale through your nose and as you exhale through your mouth reach down with your right foot.

4. Push your left hip down firmly into the mat and try to arch your left abdominal wall. You should feel your left abdominal wall engage.

5. With your left abdominal wall engaged and your right leg reaching down, push the outside border of your left foot down into the mat and "turn" your left knee up. You should feel your left inner thigh engage.

6. With your left inner thigh engaged, turn your right toes out and attempt to pick your right leg off of the bolster. You should feel your right outer hip engage.

7. Hold this position while you take $4-5$ deep breaths in through your nose and out through your mouth.

8. Relax and repeat 4 more times.

Copyright $\left(\subset\right.$ Postural Restoration Institute ${ }^{\mathrm{TM}}$ used with permission www.posturalrestoration.com 


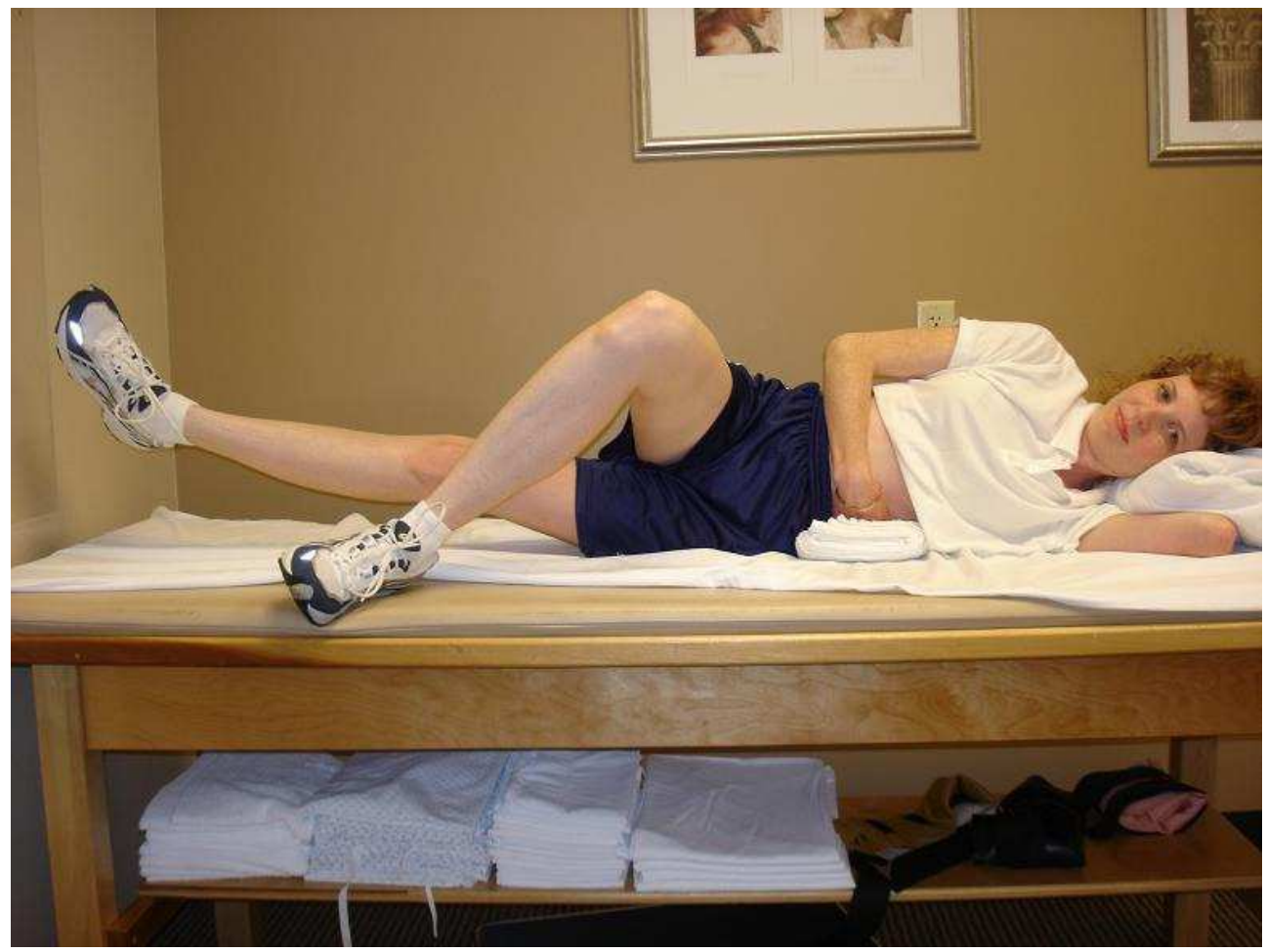

1. Lie on your left side with your left leg straight.

2. Place a 2-3 inch towel under your left side and 1-2 pillows under your head so that your neck is slightly side bent to the right.

3. Bend your right leg and cross it over your left leg.

4. Place your right foot slightly ahead of your left knee and drop the inside of your right foot toward the mat so that you can feel the arch of your foot push into your shoe.

5. Push your left hip down into the mat, bring your right knee forward and arch your left abdominal wall over the bolster. With your right hand you should feel your left abdominal wall engage. Do not engage your neck.

6. Keeping your right arch in contact with the mat, turn your right knee out. You should feel your right outside hip engage.

7. Keeping your left hip down and right knee turned out, turn your left toes up towards the ceiling and pick your entire leg up. You should feel your left inner thigh engage.

8. Hold this position while you take 4-5 deep breaths in through your nose and out through your mouth.

9. Relax and repeat 4 more times.

Fig. 25. Left Sidelying IO/TA and Left Adductor with Right Glute Max Copyright $\left(\subset\right.$ Postural Restoration Institute ${ }^{\mathrm{TM}}$ used with permission www.posturalrestoration.com 


\section{Published case studies involving Postural Restoration for L AIC patterns}

A recent case study was published describing PR management for a 65 year old female with L SIJP/SIJD, and painful intercourse. ${ }^{47}$ Left hamstrings were activated to restore optimal sagittal plane pelvic position because of the anterior tilt of the left innominate. L AF IR position was achieved and left IR muscle was activated (anterior glut med and L IC AM). R GM was activated to help train the patient to keep her L acetabulum over her L femur (L AF IR). She had a remarkable decrease in her pain from an $8 / 10$ to a $0 / 10$ and an increase in her function as measured by a change from an Oswestry Disability Index (ODI) score of $20 \%$ to $0 \% .{ }^{47}$ A case series was presented at an international meeting on four patients with SIJP. 69 There were two patients with right SIJP and two with left SIJP from 30-54 years of age. They had duration of pain from two weeks to three years, and were seen between two to seven visits over 2.5 to 3.5 weeks. The improvement in function based on the ODI change score ranged between $16-33 \%$, with a mean of $26 \%$ and an average percent improvement in function of $85 \%$. The Patient Specific Functional Scale (PSFS) was also used to measure function and the change scores ranged from 3.0-7.3 and a mean of 5.2.72 Both the ODI and PSFS exceeded the minimally clinical important difference (MCID) of 10 for the ODI and 2 for the PSFS.72, 73 Currently a RCT is underway to investigate outcomes related to pain and function comparing traditional intervention to postural restoration exercises for patients with sacroiliac joint pain. This data however is not yet published. There are four other case studies relating to a L AIC pattern where a Postural Restoration approach was used however these were not specifically for patients with SIJP, but rather LBP, ${ }^{46}$ Thoracic Outlet Syndrome, ${ }^{44}$ Asthma ${ }^{51}$ and Trochanteric Bursitis. 50

In summary, disorders involving the SIJs are relatively common and can be diagnosed using subjective history elements (pain arising from long term sitting, pain located over one SIJ (Fortin's Finger Test) and possibly into the buttock (Fortin's Area) and special tests for load transfer (ASLR) and pain provocation (e.g. posterior shear, compression). Motion palpation tests should be avoided as their reliability is poor. The Ober's Test or Adduction Drop Test may be helpful in determining the presence of pelvic asymmetry and/or ipsilateral hip flexor tone and/or adductor tone. There is motion in the SIJs, and asymmetrical laxity is associated with PGP rather than generalized bilateral SIJ laxity. Motion in the sagittal plane is greater in the R SIJ than the L SIJ. The concepts of form and form closure are important to integrate into clinical reasoning for patients with SIJP/SIJD. Force closure may be reduced or excessive in patients with SIJP/SIJD. There is a paucity of research, particularly higher levels of research to substantiate interventions for these conditions. Many lower levels of research i.e. case reports and descriptive studies do not describe the exercises used in enough detail to apply them to patient management or to replicate the studies. This chapter offered a theoretical framework and biomechanical rationale for the management of patients with right and/or left SIJP as it relates to an underlying postural pattern of asymmetry referred to as a Left Anterior Interior Chain (L AIC) pattern. Unique Postural Restoration therapeutic exercises with face validity to address the theoretical framework were also presented and described. These exercises focused on right gluteus maximus activation in the transverse plane for right SIJP/SIJD and on left anterior gluteus medius and ischiocondylar adductor magnus activation for left SIJP/SIJD. Peer reviewed and published data to highlight a theoretical framework for therapeutic exercise management of SIJP is currently lacking. Randomized controlled trials are needed to substantiate the effectiveness of all interventions 
used to manage patients with SIJP/SIJD and to compare interventions to determine which are most efficacious.

\section{References}

[1] Paris SV. Introduction to spinal evaluation and manipulation. 3rd ed. St. Augustine: Patris Press 1997.

[2] Vleeming A, Albert HB, Ostgaard HC, et al. European guidelines for the diagnosis and treatment of pelvic girdle pain. Eur Spine J 2008;17:794-819.

[3] Schwarzer AC CNA, N Bogduk. The Sacroiliac Joint in Chronic Low Back Pain. Spine 1995;20(1):31-7.

[4] Maignes JY, Aivaliklis A, Pfefer F. Results of Sacroiliac Joint Double Block and Value of Sacroiliac Pain Provocation Tests in 54 Patients With Low Back Pain. Spine 1996;21:1889-92.

[5] Ostgaard HC, Andersson GBJ, Karlsson K. Prevalence of back pain inpregnancy. Spine 1991;16(549-552).

[6] van Kessel-Cobelens AM, Verhagen AP, Mens JM, Snijders CJ, Koes BW. Pregnancyrelated pelvic girdle pain: intertester reliability of 3 tests to determine asymmetric mobility of the sacroiliac joints. J Manipulative Phys Ther 2008;31(2):130-6.

[7] van der Wurff P, Hagmeijer RHM, Meyne W. Clinical tests of the sacroiliac joint: a systematic methodological review. Part 1: reliability. Manual Therapy 2000;5(1): 30-6.

[8] Szadek KM. Diagnostic validity of criteria for sacroiliac joint pain: a systematic review. . J Pain 2009 10(4):354-68.

[9] Young S, Aprill C, Laslett M. Correlation of clinical examination characteristics with three sources of chronic low back pain. Spine 2003;3:460-5.

[10] Fortin JD, Falco FJ. The Fortin finger test: an indicator of sacroiliac pain. Am J Orthop 1997 26:477-80.

[11] Fortin JD, Dwyer AP, West S. SIJ: pain referral maps upon applying a new injection/arthrography technique. Part II: Clinical evaluation. Spine 1994;19:1483-9.

[12] O-Sullivan PB. Altered Motor Control strategies in Subjects With Sacroiliac Joint Pain During the Active Straight-Leg-Raise Test. Spine 2002;27(1):E1-E8.

[13] Lee D. The Pelvic Girdle an approach to the examinat in and treatment of the lumbopelvic-hip region. 3rd ed. New York, NY: Churchhill Livingstone, 2004.

[14] Laslett M, Young SB, Aprill CN, McDonald B. Diagnosing painful sacroiliac joint: a validity study of the McKenzie evaluation and sacroiliac provacation tests. Aust J Physiother 2003;49(2):89-97.

[15] Stuber KJ. Specificity, sensitivity and predictive values of clinical tests of the sacroiliac joint: a systematic review of the literature. J Can Chiropr Assoc 2007;51:30-41.

[16] Sizer PS, Phelps V, Thompsen K. Disorders of the sacroiliac joint. 2 2002;1:17-34.

[17] Freburger JK RD. Using Published Evidence to Guide the Examination of the Sacroiliac Joint Region. Physical Therapy 2001;81(5):1135-43.

[18] Maignes JY AA, Pfefer F. Results of Sacroiliac Joint Double Block and Value of Sacroiliac Pain Provocation Tests in 54 Patients With Low Back Pain. Spine 1996;21:1889-92.

[19] Cohen SP. Sacroiliac joint pain: a comprehensive review of anatomy, diagnosis, and teatment. . Anesth Analg 2005;101:1440-53. 
[20] Levangie P. The Vertebral Column. Joint Structure and Function A Comprehensive Analysis. Philadelphia: FA Davis Co., 2005:173-6.

[21] Sturesson B, Uden A, Vleeming A. A radiostereometric analysis of movements of the sacroiliac joints during the standing hip flexion test. Spine 2009;25(3):364-8.

[22] Smidt G, Wei S, McQuade K, Barakatt E, Sun T, Stanford W. Sacroiliac motion for extreme hip positions: a fresh cadaver study. Spine 1997;22(18):2073-82.

[23] Ivanov AA, Kiapour A, Ebraheim NA, Goel V. Lumbar fusion leads to increases in angular motion and stress across sacroliacjoint: a finite element study. Spine 2009;34(5):E162-9.

[24] Bussey MD, Bell ML, Milosavljevic S. The influence of hip abduction and external rotation on sacroiliac motion. Man Ther 2009(5):1-6.

[25] Damen L, Spoor CW, Snijders CJ, Stam HJ. Does a pelvic belt influence sacroiliac joint laxity? Clinical Biomechanics 2002;17(7):495.

[26] Vleeming A, Stoeckart R, Volkers ACW, Snijders CJ. Relation between form and funciton in the sacroiliac joint. 2: Biomechanical aspects. Spine 1990;15(2):133.

[27] Tulberg T, Blomberg S, Branth B, Johnsson R. Manipulation does not alter the position of the sacroiliac joint. A roentgen stereophotogrammetric analysis. Spine 2008;31(2):123-7.

[28] O'Sullivan PB. Diagnosis and classification of pelvic girdle pain disorders Part 1: A mechanism based approach within a biopsychosocial framework. . Man Ther 2007;12:86-97.

[29] Snijders CJ VA, Stoeckart R. Transfer of Lumbosacral Load to Iliac Bones and Legs. Clinical Biomechanics 1992;8:285-94.

[30] Richardon CA, Snijders CJ, Hides JA, Damen L, Pas MS, Storm J. The relation between the transversus abdominis muscles, sacroiliac joint mechanics and low back pain. Spine 2002;27(4):399-405.

[31] Pool-Goudzwaard AL, Marijke CPH, ten Hove S, et al. Relations between pregnancyrelated low back pain, pelvic floor activity and pelvic floor dysfunction. Int urogynecol J 2005;16:468-74.

[32] Sahrmann SA. Diagnosis and Treatment of Movement Impairment Syndromes. St. Louis: Mosby, 2002.

[33] Gibbons S. The integration of the psoas major and the deep sacral gluteus maximus muscles into the lumbar cylinder model. In: World Congress on Manual Therapy, 2005.

[34] Moore KL, Dalley AF. Clinically Oriented Anatomy. 5 ed. Philadelphia, PA: Lippincott Williams and Wilkins, 2006.

[35] Hodges PW, Butler JE, McKenzie DK, et al. Contraction of the human diaphragm during rapid postural adjustments. J Phys 1997;505(2):539-48.

[36] De Troyer A, Estenne M. Functional Anatomy of the Respiratory Muscles. Clin Chest Med 1988;9(2):175-93.

[37] Mead J. Functional significance of the area of apposition of diaphragm to rib cage. Am Rev Respir Dis 1979;11:31.

[38] Reid WD, Dechman G. Considerations when testing and training the respiratory muscles. Phys Ther 1995;75(11).

[39] DeTroyer A, Estenne M. Respiratory Anatomy of the Respiratory Muscles. Clin Chest Med 1988;9(2):175-93. 
[40] Loring SH, Mead J. Action of the diaphragm on the rib cage inferred from a forcebalance analysis. J Appl Physiol 1982;53(3):756-60.

[41] Boyle K, et al. The Value of Blowing Up a Balloon. N Am J Sports Phys Ther 2010;5(3):179-88.

[42] Lando Y, Boiselle PM, Shade D, et al. Effect of Lung Volume Reduction Surgery of Diaphragm Length in Severe Chronic Obstructive Pulmonary Disease. Am J Respir Crit Care Med 1999;159(3):796-805.

[43] Cassart M, Pettiaux N, Gevenois PA, et al. Effect of Chronic Hyperinflation on Diaphragm Length and Surface Area. Am J Respir Crit Care Med 1997;156:504-8.

[44] Robey JH, Boyle KL. Bilateral functional thoracic outlet syndrome in a collegiate football player. N Am J Sports Phys Ther 2009;4(4):170-81.

[45] Boyle K. Ethnography of the postural restoration subculture: a posture based approach to patient/client management [Dissertation]. Fort Lauderdale, FL: Nova Southeastern University, 2006.

[46] Boyle K, Demske J. Management of a Female with Chronic Sciatica and Low Back Pain: A Case Report. Physiother Theory Pract 2009;25 (1):44.

[47] Boyle K. Postural Restoration Management of a Female with Left Low Back Pain and Sacroiliac Joint Pain: A Case Report. Physiother Can 2011;63(2):154-63.

[48] Hruska R. Myokinematic Restoration An Integrated Approach to Treatment of Patterned Lumbo-Pelvic-Femoral Pathomechanics [Course manual]. Elon, NC: PRI, 2005.

[49] Boyle K. Conservative Management for patients with low back pain: a case series. JOSPT 2008;38(1):A67.

[50] Boyle K, et al. Management of a woman diagnosed with trochanteric bursitis with the use of a Protonics ${ }^{\circledR}$ neuromuscular system. Journal on the Section of Women's Health 2003;27(1):12-7.

[51] Coughlin KJ, Hruska RJ, Masek J. Cough-Variant Asthma: Responsive to Integrative Management and Postural Restoration. Explore 2005;1(5):377-9.

[52] Boyle K, Rane S. Postural Restoration management of a Female with Right Pelvic and Proximal Hamstring Pain. In: WCPT-AWP \& IAP Congress; 2009 Mumbai, India, 2009

[53] Ebmeier J, Hruska R. Postural Restoration Institute Web site. 2010 [cited 2010 1-282010]; Available from: www.posturalrestoration.com

[54] Hruska R. Postural Respiration An Integrated Approach to Treatment of Patterned Thoraco-Abdominal Pathomechanics. Chandler, AZ: Postural Restoration Institute, 2007.

[55] Reamy BV, Slakely JB. Adolescent Idiopathic Scoliosis:Review and Current Concepts. American Family Physician 2001;64:111-6.

[56] Song K, Herring JA. Early recognition and assessment of idiopathic scoliosis. J Musculoskel Med 1993;10(4):63-76.

[57] Kouwenhoven JM, et al. Analysis of preexistent vertebral rotation in the normal spine. Spine 2006;31(13):1467-72.

[58] Kouwenhoven JW, et al. The relation between organ anatomy and pre-existent vertebral rotation in the normal spine. Spine 2007;32(10):1123-8.

[59] Kendall FP, et al. Muscles Testing and Function with Posture and Pain. 5th ed. Philadelphia: Lippincott Williams and Wilkins, 2005. 
[60] Tenney R, Boyle K, Debord A. Influence of Hamstring and Abdominal Muscle Activation on a Positive Ober's Test in Subjects with Lumbo-pelvic Pain. Physiother Can 2011:in review.

[61] Boyle K, Albarran I. The Influence of Hamstring Activation on the Outcome of a Postive Ober's Test. In: APTA Annual Conference San Antonio,Texas, 2008.

[62] Masek J. Soccer Hip Impingement as it Relates to Postural Restoraiton Part III: Management Considerations. In: Perofrmance Soccer Conditioning, 2007:1-4.

[63] Boyle K. Management of patients with sacroiliac joint pain: what's old, what's new, what's in, what's out. In: Combined Sections Meeting APTA; 2010; San Diego, CA, 2010.

[64] Hruska R. Impingement and Instability [course manual]. Lincoln, NE, 2009.

[65] Stuge B, Bragelien V, Laerun E. The efficacy of a treatment program focusing on specific stabilizing exercises for pelvic girdle pain after pregnancy: a two-year follow-up of a randomized clinical trial. Spine 2004;29(10):E197-E203.

[66] Shearar KA, Colloca CJ, White HL. A randomized clinical trial of manual versus mechanical force manipulation in the treatment of sacroiliac joint syndrome. J Manipulative Phys Ther 2005;28(7):493-501.

[67] Osterbauer PJ, DeBoer KF, Widmaier R. Treatment and biochemical assessment of patients with chronic sacroiliac syndrome. J Manipulative Phys Ther 1993(16):82-90.

[68] Sasso RC, Ahmad RI, Butler JE, Reimers DL. Sacroiliac joint dysfunciton: a long-term follow-up study. In: www.orthobluejournal.com, 2001:457-60.

[69] Boyle K, Tenney R, Robey J, Gross M. Postural Restoration Management for Patients with Sacroiliac Joint Dysfunction: A Case Series. In: World Congress Physical Therapy; 2011; Amsterdam, Netherlands, 2011.

[70] Boyle K, Tenney R, Robey J, Gross M. Postural Restoration Management for Patients with Sacroiliac Joint Dysfunction: A Case Series. Physiotherapy 2011;97(1):eS1eS1638, RR-PO-205-20.

[71] Hruska R. Advanced Integration [Course manual]. Lincoln, NE: Postural Restoration Institute, 2004.

[72] Stratford P GC, Westaway M, Binkley J. Assessing disability and change on individual patients: a report of patient specific measure. Physiotherapy Canada 1995;47(4): 258-63.

[73] Ostelo RWJG, deVet HCW. Clinically important outcomes in low back pain. Best Pract Res Clin Rheumatol 2005;19(4):593-607. 


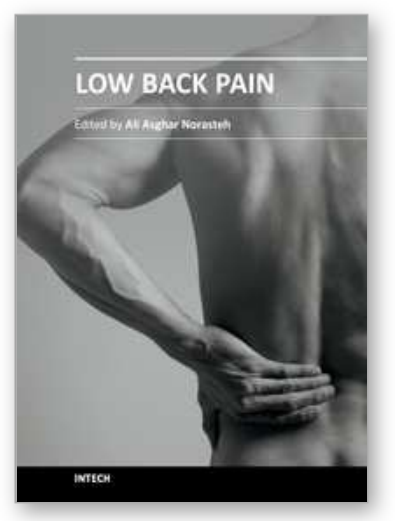

\section{Low Back Pain}

Edited by Dr. Ali Asghar Norasteh

ISBN 978-953-51-0599-2

Hard cover, 352 pages

Publisher InTech

Published online 09, May, 2012

Published in print edition May, 2012

This book includes two sections. Section one is about basic science, epidemiology, risk factors and evaluation, section two is about clinical science especially different approach in exercise therapy. I envisage that this book will provide helpful information and guidance for all those practitioners involved with managing people with back pain-physiotherapists, osteopaths, chiropractors and doctors of orthopedics, rheumatology, rehabilitation and manual medicine. Likewise for students of movement and those who are involved in re-educating movement-exercise physiologists, Pilates and yoga teachers etc.

\section{How to reference}

In order to correctly reference this scholarly work, feel free to copy and paste the following:

Kyndall Boyle (2012). Conservative Management for Patients with Sacroiliac Joint Dysfunction, Low Back Pain, Dr. Ali Asghar Norasteh (Ed.), ISBN: 978-953-51-0599-2, InTech, Available from:

http://www.intechopen.com/books/low-back-pain/conservative-management-for-patients-with-sacroiliac-jointdysfunction

\section{INTECH}

open science | open minds

\section{InTech Europe}

University Campus STeP Ri

Slavka Krautzeka 83/A

51000 Rijeka, Croatia

Phone: +385 (51) 770447

Fax: +385 (51) 686166

www.intechopen.com

\section{InTech China}

Unit 405, Office Block, Hotel Equatorial Shanghai

No.65, Yan An Road (West), Shanghai, 200040, China

中国上海市延安西路65号上海国际贵都大饭店办公楼 405 单元

Phone: +86-21-62489820

Fax: +86-21-62489821 
(C) 2012 The Author(s). Licensee IntechOpen. This is an open access article distributed under the terms of the Creative Commons Attribution 3.0 License, which permits unrestricted use, distribution, and reproduction in any medium, provided the original work is properly cited. 